\title{
BIBLIOGRAFfA
}

\section{SECGIONN GENERAL}

\section{OBRAS BIBLIOGRĀFICAS}

1008丂. Bibliografia. - NRFH, 8 (1954), 100-133. - V. núm. 9ogo.

10086. Malclès, L.-N. - Les sources $d u$ travail bibliographique. - Droz, Genève, 1950-1952. 2 ts.: $3^{80}$ y $9^{60} \mathrm{pp}$.

10087. Palau y Dulcet, Antonio - $M a$ nual del librero hispanoamericano. Bi. bliografia general española e hispanoamericana. $2^{\text {a }}$ ed. T. 5: E-F.-Librería Palau, Barcelona, 1951. $54^{\circ}$ pp. - V. núm. 8387 .

10088. Bridgwater, William, \& ElizaBETH J. SHERWOOd (eds.) - The Columbia Encyclopedia. and ed. - Columbia Univ. Press, New York, $195^{\circ}$. $1 v+2203$ pp.

10089. Bershas, Henry N. - Sobre: W. Bridgwater \& E. J. Sherwood (eds.), The Columbia Encyclopedia. - MLJ, $3^{8}$ (1954), 157-159. [Critica la parte relativa a España e Hispanoamérica].

10090. American bibliography, 195I. PMLA, 67 (1952), núm. 3 B. [General (and miscellaneous) section by $\mathbf{P}$. A. Brown; Spanish and Portuguese language and literature by E. B. Williams, B. L. O. Richter, and A. G. Reichenberger].

10091. Aston, S. C. (ed.) - The year's work in modern language studies. T. 12: 1950. - Cambridge University Press, 1951 [publ. 1952]. viii +363 pp. [Español y catalán por I. González Llubera, F. Pierce y H. F. Grant].

loog2. Vindel, Francisco - El arte tipográfico en España durante el siglo $x v$. T. 8: Dudosos de lugar de impresión. Adiciones y correcciones. T. 9: Indices generales. - Dir. Gral. de Relaciones Culturales, Madrid, 1951. Xxxv + 392 y 135 pp. - V. núm. $77^{15}$.

10093. Vindel, Francisco - Escudos y marcas de impresores y libreros en España durante los siglos xv a xix (1485.
1850). - Orbis, Barcelona, [1951]. V. núm. 6077 .

10094. Homenaje a José Toribio Medina. - $A$, sept.-oct. de $195^{2} .530$ pp.

10095. Pérez Cabrera, J. M. - Don José Toribio Medina, ciudadano y gloria de América. - Acad. de la Historia, La Habana, 1952.

10096. Donoso, Ricardo - Medina intimo. - Imp. Universitaria, Santiago de Chile, 1953.

10097. UlloA, Alberto - "El centenario de José Toribio Medina". - $M d S, 8$ (1952), núm. 23, 87-88.

10098. Silva Castro, Raúl - "El centenario de José Toribio Medina: 18521952". - RIB, 2 (1952), 3-6.

10099. ZAMudro Z., JORGE - "Medina y la bibliografia". - A, 107 (1952), 421$5^{14}$.

10100. Carreño, Alberto Ma. - "José Toribio Medina y la bibliografía". Abs, 17 (1953), 91-108.

10101. González de Cossío, Francisco La imprenta en México (1553-1820). 510 adiciones a la obra de José Toribio Medina. - Universidad de México, 1952. xvii + 354 pp., con muchos facsímiles. - V. núm. 2093.

10102. Millares Carlo, Agustín - "Dos datos nuevos para la historia de la imprenta en México en el siglo xvr". NRFH, 7 (1953), 702-708.

10103. MEDINA, Jose Toribio - Contribución a la historia de la imprenta en Venezuela. Presentación y notas de Pedro Grases. -Caracas, 1952. 69 pp.

10104. Senior, Clarence O., \& Josefina DE ROMÁN (compils.) - $A$ selected bibliography on Puerto Rico and the Puerto Ricans. - [New York, 1951]. $32 \mathrm{pp}$.

10105. Peraza Sarausa, Fermín - Dic. cionario biográfico cubano. - La Habana, 1951. T. 1 (Biblioteca del bibliotecario, núm. 36).

10106. Peraza Sarausa, F. - Directorio de bibliotecas de Cuba. - Anuario Biblio- 
gráfico Cubano, La Habana, 1950. 62 pp. (Biblioteca del bibliotecario, 2).

10107. Barretr, L. L. - "The cultural scene in Ecuador: 1951". - HispB, 35 (1952), 441-442.

10108. Anuario bibliográfico peruano de 1948. - Biblioteca Nacional del Perú, Lima, $195^{1 .}$

10109. Catálogo de publicaçōes periódicas da Universidade de São Paulo. - São Paulo, 1951. $5^{2}$ pp. [Mimeografiado]. 10110. Pendee, G. - "The Latin American reviews”. - TTC, 149 (1951), núm. $887,48-54$.

1011. Walford, Albert John. - "Latin Americana in British libraries and archives". - RIB, 1 (1951), 174-177.

10112. Bibliografía filosófica del siglo $x \mathrm{x}$. - Eds. Peuser, Buenos Aires, $195^{2}$. $468 \mathrm{pp}$.

V. también núms. 10115, 10218, 10323-26, $10439-40,1045^{0}, 10470-71,10475-76$, $10517-19,10644,10707,10749-51,10811$, 10813.

\section{HISTORIA}

10119. Croce, Benedetro - La storia come pensiero e come azione. $5^{\text {a }}$ ed. Laterza, Bari, 1952. viii + 354 pp.

10114. Croce, Benedetro - Teoria e historia de la historiografía. - Imán, Buenos Aires, 1953. 300 pp.

10115. Sarton, George (ed.) - "Critical bibliography of the history and philosophy of science and of the history of civilization". - Isis, 42 (1951), 309-395; 43 (1952), 128-208.

10116. LOT, FERDINAND - La fin du monde antique et le début du moyen âge. Albin Michel, París, 1951. 560 pp.

10117. Delmas, Claude - "Structure et limites du moyen âge: l'œuvre de Ferdinand Lot". - Crit, 9 (1953), 438-452.

10118. HALPHEN, DANIEL - Initiation aux études d'histoire du moyen age. $3^{\text {a }}$ ed. - Paris, 1952. xv + 205 pp.

10119. Vedel, ValdFmar - Ideales culturales de la Edad Media. I: Vida de los héroes. $4^{\mathrm{a}}$ ed. - Labor, Barcelona, [1952]. 199 pp. (Col. Labor, 29).

10120. Burch, George B. - Early medieval philosophy. - K. Crown's Press, Columbia Univ., 1951. viii + 142 pp. 10121. RiIsing, ANNE - "The fate of Henri Pirenne's thesis on the consequences of the Islamic expansion". CM, 13 (1952), núm. 1 .

10122. Merêa, Paulo - Estudos de direito hispânico medieval. - Universidade, Coimbra, 1952. xxviii +221 pp.
10123. Holmes, Urban T. - Daily living in the twelfth century. - The University of Wisconsin Press, Madison, 1952. vi $+337 \mathrm{pp}$.

10124. Chiappini, Aniceto - Annales $M i$ norum. T. 3o. - Quaracchi, Roma, 1951. xxx + 694 pp. [Continuación de la obra de Lucas Wadding].

10125. Huizinga, J. - El otoño de la Edad Media. [Trad. J. Gaos]. $4^{\text {a }}$ ed. Rev. de Occidente, Madrid, 1952. 449 pp.

10126. Lagarde, Georges de - "La conception médiévale de l'ordre en face de l'Humanisme, de la Renaissance et de la Réforme". - Umanesimo $e$ scienza politica. Atti del Congreso Internazionale di Studi Umanistici, Roma, Firenze, 1949. Marzorati, Milano (1951), 237-245.

10127. Patton, J. Morton - Mediaeval and Renaissance visitors to Greek lands, Turkish Athens. - Princeton Univ. Press, 1951. xii + $212 \mathrm{pp}$.

10128. Sellery, Georce C. - The Renaissance: its nature and origins. - University of Wisconsin Press, Madison, 1950. $296 \mathrm{pp}$.

10129. Bullough, G. - Sobre: G. C. SeIlery, The Renaissance: its nature and origins. - MLR, $4^{8}$ (1953), $45^{6-457}$.

1013o. Penrose, Bores - Travel and discovery in the Renaissance, 1420-1620.Harvard Univ. Press, Mass., 1952. xvi + $369 \mathrm{pp}$.

10131. Pastor, Ludovico - Historia de los papas en la época del Renacimiento $y$ de la Reforma, desde la elección de León X hasta la muerte de Clemente VII. Versión de Ramón Ruiz Amado. Gustavo Gili, Barcelona, 1951-52. Ts. 8 . 10: 468,418 y $435 \mathrm{pp}$.

10132. HyMA, Albert - From Renais. sance to Reformation: $A$ review of the spiritual and temporal influence on medieval Europe. - B. Eermans, Grand Rapids, Michigan, 1951. $591 \mathrm{pp}$.

10133. Gilmore, Myron P. - Sobre: A. Hyma, From Renaissance to Reformation. - Sp, 28 (1953), 170-174.

10134. Strohl, H. - La pensée de la Réforme. - Neuchâtel, 1951.

10135. Wicki, Hans - Sobre: H. Strohl, La pensée de la Réforme. - Era, 5 (1952), 222-223.

10136. Mesnard, Pierre - L'essor de la philosophie politique au $x v i^{8}$ siècle. J. Vrin, Paris, 1951. viii + 712 + 24 pp. (Bibliothèque d'histoire de la philoso- 
phie). [Maquiavelo, Erasmo, Bodin, Suárez, etc.].

10137. Vernière, Paul - "Le spinozisme et l'Encyclopédie". - RHLF, $5^{1}$ (1951), $347-35^{8}$.

Espa ̃̃ $a$

10138. Menéndez Ptdal, R. - Los españoles en la historia y en la literatura. Espasa-Calpe, Buenos Aires, 1951. 236 pp.

10139. Legendre, MaURICE - Nueza historia de España. Trad. S. Bea. - Librería General, Zaragoza, $195^{1}$.

10140. Pemán, J. M. - Breve historia de España. - Cultura Hispánica, Madrid, 1951 .

10141. Vossler, KarL - España y Euro$p a$. - Inst. de Estudios Políticos, Madrid, 1951. $205 \mathrm{pp}$.

10142. VOSSLER, KARL - Spanien und Europa. - Kosel Verlag, München, 1952. $206 \mathrm{pp}$.

10143. GonzÁlez López, E. - Sobre: A. Castro, España en su historia. - RHM, 18 (1952), $179-180$.

10144. Prati de Fernández, M. VictoriaSobre: A. Castro, España en su histo. ria. $-\log , 6$ (1951), 245-252.

10145. SÁnchez, Alberto - Sobre: A. Castro, España en su historia. - RFE, 36 (1952), 322-332.

10146. CAstro, AmÉrico - "En el umbral de la historia". - NRFH, 7 (1953), 242245 .

10147. CAstro, Américo - "La tarea de historiar". - CCL, 1954, núm. 4, 21-25. 10148. CAstro, Américo - "Acerca de la histórica inseguridad de los españoles". - CCL, 1954, núm. 5, 82-84.

10149. SÁnchez Albornoz, C. - "Sobre historia española". - CCL, 1954, núm. $5,75^{-81}$.

10150. Castro, Américo - "Un aspecto del pensar hispano-judio". - Hisp $B, 35$ (1952), 161-172.

10151. Menéndez Pidal, Gonzalo - Los caminos en la historia de España. Cultura Hispánica, Madrid, 1951. 140 pp.

10152. Bosch Gimpera, P. - "La formazione dei popoli della Spagna". - PPN, 4 (1949), 1-129.

10153. SÁnchez-Albornoz, Nicolás - Sobre: L. Pericot García, La España primitiva. - CuHE, 1951, núm. 16, 172174.

10154. Triviño, J. M. - Sobre: A. García y Bellido, Hispania Graeca. - CuHE, 1951, núm. 15, 181-184.
10155. Bosch Gimpera, P. - "Una guerra entre cartagineses y griegos en España. La ignorada batalla de Artemision". Cuadernos de Historia Primitiva, 5 (1950), 43-55.

10156. Taracena Aguirre, B. - "El problema de los ligures en España". - $R i$. vista di Studi Liguri, 17 (1951), núm. 2. 10157. HüffER, H. J. - "Las relaciones hispanogermanas durante mil doscientos años". - RevEP, 36 (1951), 43-76.

10158. Udina Martorell, F. - "Consideraciones acerca de los inicios del Medioevo hispánico y la alta reconquista". - HispM, 11 (1951), núm. 43.

10159. Sánchez Candeira, Alfonso - $E l$ "Regnum-Imperium" leonés hasta 1037. -C.S.I.C., Madrid, 1951. 73 pp.

1016o. Isola, Emma - Sobre: Ch. J. Bishko, Salvus of Albelda and frontier monasticism in tenth-century Navarra. CuHE, I951, núm. 16, 176-179.

10161. Mansilla, D. - "Episcopologio de Burgos. Siglo Xuı'. - HS, 4 (1951), 313333.

10162. Rivera Recio, J. F. - "Personajes hispanos asistentes en 1215 al IV Concilio de Letrán”.-HS, 4 (1951), núm. 8. 10163. Pietri, Francisco - Vecindad histórica (españoles y franceses). - Cultura Hispánica, Madrid, 1951.

10164. Reglá Campistol, J. - Francia, la Corona de Aragón y la frontera pire. naica. La lucha por el Valle de Arán (siglos xiii-xiv). - C.S.I.C., Madrid, 1951. 2 ts.: xvi $+33^{2}$ y 482 pp.

10165. Higounet, C. - Sobre: J. Reglá Campistol, Francia, la Corona de Aragón y la frontera pirenaica. - BHi, 54 (1952), 425-427.

10166. Benito Ruano, E. - "España y las cruzadas”. - $A H A, 195^{1-1952,92-120 .}$

10167. Sabatino López, Roberto - "Alfonso el Sabio y el primer almirante genovés de Castilla". - CuHE, 1950, núm. $14,5^{-16}$.

10168. LONGNON, JEAN - "La domination catalane en Grèce". - Journal des Savants, 1951, 107-121. [Sobre los libros de A. Rubió i Lluch y de K. M. Setton].

10169. Carlé, M. del Carmen - "El precio de la vida en Castilla, del Rey Sabio al Emplazado". - CuHE, 1951, núm. $15,192-156$.

10170. Jiménez Soler, ANdrés - "Los judios españoles a fines del siglo xIv $y$ principios del $x v^{\prime \prime}$. - UnivZ, 27 (1950), núms. 2-3.

10171. Gual Camarena, M. - "Las tre- 
guas de Majano entre Aragón, Navarra y Castilla (1430)." - CuHE, 1951, núm. 16, 79-109.

10172. SuÁrez Fernández, Luis - "Herencia medieval de Castilla". - RevEP, 35 (1951), 127-140.

10173. Corominas, Pedro - El sentimiento de la riqueza en Castilla. Por Castilla adentro. - Aguilar, Madrid, 1951. 479 pp.

10174. Majó Framis, Ricardo - Tanto monta. Ensayo biográfico de los Reyes Católicos y relato, interpretación y glosa de $s u$ reinado. - Edit. Nacional, $\mathrm{Ma}$ drid, 1951. 554 pp.

10175. Benito Ruano, Eloy - "El centenario de los Reyes Católicos".- $R A B M$, 57 (1951), 697-710.

10176. TORre, Antonio de LA (ed.) - Documentos sobre relaciones internacionales de los Reyes Católicos. T. 3: 1488-149x. - C.S.I.C., Madrid, 1951. 601 pp. - V. núm. 9217.

10177. Ándrés, Alfonso - "Documentos originales de los Reyes Católicos en archivos particulares (1458-1515)". $R A B M, 57$ (1951), 637-656.

10178. Mata Carriazo, Juan DE - "Tres cortesanos de los Reyes Católicos: Gonzalo Chacón, Gutierre de Cárdenas y don Diego Hurtado de Mendoza. (Semblanzas ejemplares de Gonzalo Fernández de Oviedo)".-Clav, 2 (1951) núm. $12,9-18$

10179. Corderro de Sousa, J. M. - "Apuntes sobre la vida y muerte de la reina Doña María, hija de los Reyes Católicos". - RABM, 57 (1951), 657-696.

10180. Sarrablo, Eugenio - "Una alianza angloespañola del siglo xvi”. $-R A B M$, 57 (1951), 579-598.

10181. Sfelke de SÁnchez, ÁNGela - "Algunos datos nuevos sobre los primeros alumbrados. El edicto de $\mathbf{1 5 2 5}$ y su relación con el proceso de Alcaraz". BHi, 54 (1952), 125-152.

10182. ASENSIO, EUGENIO - "El erasmismo y las corrientes espirituales afines". $R F E, 3^{6}$ (1952), 31-98.

10183. A [Ubrun], C. V. - Sobre: M. Bataillon, Erasmo y España, trad. A. Alatorre. - BHi, 54 (1952), 94-95.

10184. GreEN, O. H.-Sobre: M. Bataillon, Erasmo y España, trad. A. Alatorre. $H R$, 20 (1952), 75-77.

10185. Lida DE Malkiel, M. R. - Sobre: M. Bataillon, Erasmo y España, trad. A. Alatorre. - RomPh, 7 (1953-54), p. 401 .

10186. PeErs, E. A. - Sobre: M. Bataillon,
Erasmo y España, trad. A. Alatorre. BHS, 29 (1952), $121-122$.

10187. REY, A. - Sobre: M. Bataillon, Erasmo y España, trad. A. Alatorre. $S, 6$ (1952), 225-229.

10188. Santullano, Luis - Sobre: M. Bataillon, Erasmo y España, trad. A. Alatorre. $-N D, 3^{1}$ (1951), 2, 64-72.

10189. WoOdbridge, H. C. - Sobre: M. Bataillon, Erasmo y España, trad. A. Alatorre. - HispB, 35 (1952), 126.

1019o. SÁnchez Montes, JUAN-Franceses, protestantes, turcos. Los españoles ante la politica internacional de Carlos $\boldsymbol{V}$. C.S.I.C., Madrid, 195̆1. 167 pp.

10ig1. Bataillon, M. - Sobre: J. Sánchez Montes, Franceses, protestantes, turcos. Los españoles ante la politica internacional de Carlos V. - BHi, 54 (1952), 208-211.

10192. Favre-Dorsaz, AndrÉ - Calvin et Loyola. Deux réformes. - Éds. Universitaires, Paris-Bruxelles, 1951. $457 \mathrm{pp}$. 10193. Gutiérrez, Constancio - Españo. les en Trento. - C.S.I.C., Valladolid, 1951. lxviii + 1059 pp.

10194. Cortés, Vicenta - Sobre: C. Gutiérrrez, Españoles en Trento.-RevEP, 42 (1952), 162-163.

10195. Pérez Bustamante, C. - "El pontífice Paulo $\mathrm{V}$ y la expulsión de los moriscos". - $B A H, 129$ (1951), 219-233.

10196. Fornieles, Salvador - La España del siglo xvi. (Felipe II y la Inquisición). - Ateneo, Buenos Aires, 1951. $155 \mathrm{pp}$.

10197. Koentgsaerger, Helmut - The government of Sicily under Philip II of Spain. A study in the practice of Empire. [Pról. de J. M. Batista y Roca]. - London, 1951. 227 pp.

10198. Fernández Alvarez, Manuel Tres embajadores de Felipe II en Inglaterra. - C.S.I.C., Madrid, 1951. 322 pp. 10199. Seco Serrano, C. - Sobre: M. Fernández Alvarez, Tres embajadores de Felipe II en Inglaterra.-Arb, 24 (1953), 257-26o.

10200. SANCHEZ Y Escribano, F. - Cosas y casos de los albores del siglo xvii español. Antologia de hechos espigados de memorias escritas entre $1599 y$ 1614. - Hispanic Inst., New York, 1951. $117 \mathrm{pp}$.

10201. Carballo Picazo, A. - Sobre: C. Pérez Bustamante, Felipe III. Semblanza à un monarca y perfiles de una pri. vanza. - RBD, 5 (1951), 292-293.

10202. Marañón, Gregorio - Il Conte Duca di Olivares. La passione del co- 
mando. - Longanesi, Milano, 1951. $331 \mathrm{pp}$.

10203. SÁNChez-Albornoz, N. - Sobre: J.M. Jover, 1635: Historia de una polémica y semblanza de una generación. $C u H E$, 19.51, núm. 16, 183.19o.

10204. Rodrfguez, Hernán - Sobre: O. V. Quiroz Martínez, La introducción de la filosofia moderna en España. - NEF, 3 (1952), 77-78.

10205. Rodrf́guez Casado, Vicente - "La revolución burguesa del xvirr español". - $A r b, 18$ (1951), 5-30.

10206. Aunós, Eduardo - Romanticismo $y$ politica. - Soc. Gral. Española de Libreria, Madrid, 1951. $383 \mathrm{pp}$.

Portugal

10207. Queirós Veloso, José M. de - Es tudos históricos do século xvi. - Acad. Portuguesa da História, Lisboa, $195^{\circ}$. $209 \mathrm{pp}$.

10208. Bernard-Maître, Henri - "Un grand serviteur du Portugal en France, Diogo de Gouveia l'ancien et le Collège Sainte-Barbe de Paris (1520-1548)". $B E P I, 15$ (1951), 3-75.

10209. Verf́ssimo Serrão, J. - "Le juris consulte Antoine de Gouveia à l'Université de Valence en Dauphiné (1554. 1555)". - BEPI, 16 (1952), 96-133.

10210. BRandão, Mário - A Inquisição e os professores do Colégio das Artes. Acta Univ. Conimbrigensis, Coimbra, 1948. xii + 694 pp.

10211. Dalmases, C. DE - Sobre: Mário Brandão, A Inquisição $e$ os professores do Colégio das Artes.-AHSI, 21 (1952), $162-163$.

10212. Cortesĩo, JaIme - Alexandre de Gusmão e o Tratado de Madrid (1750). Parte III: Antecedentes do Tratado. 2 ts. - Inst. Rio-Branco, Rio de Janeiro, 1951. 546 pp. cada tomo.

10213. Fernand de Almeida, Luís - Sobre: J. Cortesão, Alexandre de Gusmão $e$ o Tratado de Madrid (1750). - Biblos, 28 (1952), 499-515.

Hispanoamérica

10214. Bermúdez Plata, Cristóbal - El Archivo general de Indias de Sevilla, sede del Americanismo.-Madrid, $195^{1 .}$ $40 \mathrm{pp}$.

10215. MCINnIs, EDGAR y otros - Ensayos sobre la historia del Nuevo Mundo. Inst. Panamericano de Geografía e Historia, México, 1951. xii $+497 \mathrm{pp}$.

10216. RICARD, R. - Sobre: E. McInnis y otros, Ensayos sobre la historia del Nuevo Mundo. - BHi, 54 (1952), 224225.

10217. Davis, Harold E. - Sobre: E. McInnis y otros, Ensayos sobre la historia del Nuevo Mundo. - HAHR, 39 (1953), 97-101.

10218. Vérez de Peraza, Elena L. - Bibliografia colombina. - Soc. Colombista Panamericana, La Habana, 1951. 14 pp.

10219. Madartaga, Salvador de - Christoph Columbus. (Vida del Muy Magnifico Señor Don Cristóbal Colón). Das Leben des sehr hochmögenden Señor Don Cristóbal Colón. [Trad. al. por Raymond Bérenger]. - Deutsche Verlags-Anstalt, Stuttgart, 1951. 544 pp. 10220. Vespucio, AMÉrico - El Nuevo Mundo. Cartas relativas a sus viajes $y$ descubrimientos. Textos en italiano, español $e$ inglés. Estudio de Roberto Levillier. - Nova, Buenos Aires, 1951. $34^{2}$ pp.

10221. Nowell, Charles E. - Sobre: Américo Vespucio, el Nuevo Mundo, ed. R. Levillier. - HAHR, $3^{2}$ (1952), 110-111.

10222. Caraci, Giuseppe - "A propósito de Amerigo Vespucci". - RHSP, 3 (1952), núm. 11, 189-194.

10223. Caraci, Giuseppe - “Amerigo Vespucci e um moderno crítico argentino". - RHSP, 3 (1952), núm. 12.

10224. Guglielmi, Nilda - Sobre: F. Pérez Embid, Los descubrimientos en el Atlántico hasta el tratado de Tordesillas. - CuHE, 1951, núm. 16, 182-183. 10225. O'Gorman, Edmundo - La idea del descubrimiento de América. - Centro de Estudios Filosóficos, [México], 1951. 417 pp.

10226. Bataillon, Marcel - "L'idée de la découverte de l'Amérique chez les espagnols du $\mathrm{XvI}^{\mathrm{e}}$ siècle". - $\mathrm{BH} i, 55$ (1953), 23-55. [Sobre La idea del descubrimiento de América, de Edmundo O'Gorman].

10227. Salmerón, F. - Sobre: E. O'Gorman, La idea del descubrimiento de América. - CuA, 11 (1952), 2, 191-199. 10228. Gaos, J. - Sobre: E. O'Gorman, La idea del descubrimiento de América. $-H M x, 1$ (1951-52), 468-493.

10229. Cardiel ReYes, R. - Sobre: E. O'Gorman, La idea del descubrimiento de América. - FyL, 40 (1950), 355-356. 1023o. Maravall, José Antonio - "El descubrimiento de América en la his- 
toria del pensamiento político". RevEP, 43 (1952), 229-248.

10231. Garcfa Samudio, Nicolás - "El descubrimiento espiritual de América". - RevIndM, 11 (1951), 485̆-500. 10232. Carro, Venancio D. - La teologia y los teólogos-juristas españoles ante la conquista de América. $2^{\mathrm{a}}$ ed. - Salamanca, 1951. 700 pp. (Biblioteca de Teólogos Españoles, 18).

10233. Rabassa, Gregory - Sobre: A.M. Salas, Las armas de la conquista. RHM, 17 (1951), $158-159$.

10234. Friede, J. - "The Catálogo de pasajeros and Spanish emigration to America to ${ }^{1550 "}$ ". $-H A H R, 3^{1}(1951)$, $333-34^{8}$.

10235. Manzano Manzano, Juan - Historia de las recopilaciones de Indias. I: Siglo xvi. - Cultura Hispánica, Madrid, $195^{\circ}$.

10236. Góngora, Mario - Sobre: J. Manzano Manzano, Historia de las recopilaciones de Indias. - RChHG, 1952, núm. $119,308-310$.

10237. Lacas, M. M. - "The encomienda in Latin-American history: a reapraisal". - Amer, 8 (1951-52), 259-288.

10238. Garcfa Gallo, Alfonso - "El encomendero indiano". - RevEP, 35 (1951), 141-162.

10239. Furlong, Guillermo - "Las universidades de la América Hispana con anterioridad a 1810." - Est, 84 (1951), $139^{-1} 51$.

10240. Konetzke, Richard - "Estado y sociedad en las Indias". - Est $A, 3$ (1951), 33-58.

10241. Góngora, Mario - El Estado en el derecho indiano, época de fundación (1492-157o) - Univ. de Chile, Santiago de Chile, 1951. 328 pp.

10242. RiCARD, R. - Sobre: M. Góngora, El Estado en el derecho indiano.- $\mathrm{BHi}$, 54 (1952), 221-224.

10243. Garcfa Gallo, Alfonso - "El Derecho indiano y la independencia de América". - RevEP, $4^{\circ}$ (1951), 157180.

10244. SAbor Vila, SARa - Sobre: G. Furlong, La cultura femenina en la época colonial. - RHA, 1951, núm. 32, 256261.

10245. Navarro, Bernabé - "Los jesuitas y la independencia". $-A b s, 16$ (1952), 43-62.

10246. Matilla Tascón, A. - "Las expediciones o reemplazos militares enviados desde Cádiz a reprimir el movimiento de independencia de Hispanoamérica". $R A B M, 57$ (1951), 37-52.

10247. Tudisco, Antonio - Sobre: J. Delgado, La independencia de América en la prensa española. - RHM, 17 (1951), 160-161.

10248. Recasens Stches, Luis - "El pensamiento filosófico, social, político y jurídico en Hispano-América". - $R C F$, 2 (1951), núm. 9, 34-38.

10249. ZEA, Leopolno - Sobre: La fllosofia latinoamericana contemporánea, ed. A. Sánchez Reulet. - RIB, 1 (1951), 202-204.

10250. Palm, E. W. - "Dos relaciones acerca de la Española en el siglo xvin”. $A n U S D, 14$ (1949), 213-246.

10251. Garcfa Pons, C. - El obispo Espada y su influencia en la cultura cubana. - La Habana, 1951. 288 pp.

10252. Pleraza Sarausa, Fermín - Sobre: C. García Pons, El obispo Espada y su influencia en la cultura cubana. RHA, 1951, núm. 32, 261-263.

10253. Hernández Travieso, Antonio El Padre Varela. Biografia del forjador de la conciencia cubana. - J. Montero, La Habana, 1949. $4^{60}$ pp.

10254. Corbitt, Duvon G. - Sobre: A. Hernández Travieso, El Padre Varela. HAHR, 33 (1953) 268-69.

10255. OrRego Vicuña, Eugenio - Vicuña Mackenna y la independencia de Cuba. E1 Siglo XX, La Habana, 195ı. 37 pp. 10256. Válgoma y Diaz-Varela, DalmiRO DE LA - Linaje y descendencia de Hernán Cortés, conquistador de Méjico. - Cultura Hispánica, Madrid, $195^{1 .}$

10257. Gallegos Rocafull, José M. - El pensamiento mexicano en los siglos xvi y xvii. - Centro de Estudios Filosóficos, México, 1951. $426 \mathrm{pp}$.

10258. Bravo UGarte, José - Sobre: J. M. Gallegos Rocafull, El pensamiento mexicano en los siglos xvi y xvii. RHA, 1952, núm. 33, 135-137.

10259. Romanell, Patrick - Sobre: J. M. Gallegos Rocafull, El pensamiento mexicano en los siglos xvi y xvii.-HAHR, 32 (1952), 404-406.

10260. Mendoza, Vicente T. - Vida y costumbres de la Universidad de México. - Inst. de Investigaciones Estéticas, México, D. F., 1951. $71 \mathrm{pp}$.

10261. Jiménez RuedA, J. - Las constituciones de la antigua Universidad. - México, 1951.

10262. Martínez del Rlo, Pablo - "La Real y Pontificia Universidad de México". - CuA, 10 (1951), 5, 141-169. 
10263. Hernández Luna, J. - "La Universidad Nacional de México". - $C u A$, 10 (1951), 5, 170-199.

10264. Castro Leal, A. - "Cuatro siglos de la Universidad de México". - ND, 32 (1952), núm. 2, 64-73.

10265. Diaz y de Ovando, Clementina - El Colegio Máximo de San Pedro y San Pablo. - Ediciones del IV Centenario de la Universidad de México, México, 1951. $177 \mathrm{pp}$.

10266. Bravo Ugarte, José - Sobre: C. Díaz y de Ovando, El Colegio Máximo de San Pedro y San Pablo. - RHA, 1952, núm. 33, 133-135.

10267. Batalllon, Marcel - "L'iñiguiste et la beata. Premier voyage de Calisto à Mexico". - RHA, 1951, núm. 31, 59-75. [Sobre Calisto de Sá, compañero de San Ignacio de Loyola].

10268. Miranda, José - "Renovación cristiana y erasmismo en México". - HMx, $1\left(195^{1-52)}, 22-47\right.$.

10269. ZeA, LeOPOLdo - "Medio siglo de filosofía en México". - FyL, 21 (1951), núms. 41-42, 111-131.

1027o. Scholes, France V. - "Franciscan missionary scholars in Colonial Central America". - Amer, 8 (1951-52), 391-416. 10271. Chamorro, Pedro Joaquín - Historia de la Federación de la América Central $(1823-1840)$. - Cultura Hispá. nica, Madrid, 1951 .

10272. T[номаs], J. E. - Sobre: P. J. Chamorro, Historia de la Federación de la América Central. - CuH, 13 (1952), 276-280.

10273. LAMAdrid, Lázaro - “A survey of the historiography of Guatemala since 1821". - Amer, 8 (1951-52), 189-202, $305-320$.

10274. Barón Castro, Rodot.fo - Reseña histórica de la Villa del Salvador. Cultura Hispánica, Madrid, $195^{1 .}$

10275. Arcila Robledo, Gregorio - Las misiones franciscanas en Colombia. Es. tudio documental. - Imprenta Nacional, Bogotá, 1951. 508 pp. - V. núm. 5946.

10276. LAMAdRID, LAZARo - Sobre: G. Arcila Robledo, Las misiones franciscanas en Colombia. - Amer, 9 (1952-53), 251-253.

10277. Siso, Carlos - La formación del pueblo venezolano. - García Enciso, Madrid, 1951. 2 ts.

10278. VILLA, J. DE LA - Sobre: Carlos Siso, La formación del pueblo venezolano. - RevEP, $3^{8}$ (1951), 135-136.

10279. Frank, Waldo - Birth of a world:
Bolivar in terms of his people. Houghton Mifflin Co., Boston, $195^{1 .}$

10280. BORJA Y BORJA, RAMIro - Las constituciones del Ecuador. - Cultura Hispánica, Madrid, 1951.

10281. Porras Barrenechea, Raúl - $M i$ to, tradición e historia del Peru. Impr. Santa María, Lima, 1951. 100 pp. 10282. Pino Ycaza, Gabriel - El muy magnifico señor Gonzalo Pizarro. Guayaquil, 1950. $287 \mathrm{pp}$.

10283. Eguiguren, Lurs A. - La Universidad Nacional Mayor de San Marcos. Lima, 1951. 283 pp.

10284. Valle, Rafael Heliodoro - Sobre: L. A. Eguiguren, La Universidad Nacional Mayor de San Marcos. RHA, 1951, núm. 32, 253-255.

10285. Gento SAnz, B. - Sobre: L. A. Eguiguren, Diccionario histórico cronológico de la Real y Pontificia Universidad de San Marcos y sus colegios. $R I B, 2$ (1952), 72-74.

10286. Batalllon, M. - "Une Université du Nouveau Monde: San Marcos de Lima". - AESC, 7 (1952), 337-343.

10287. Eguiguren, L. A. - "La Universidad más antigua de América". - RHist, 40 (195I), 8-17.

10288. Rojas DfAz, B. - "La Universidad Nacional Mayor de San Marcos y el sabio peruano doctor 'Federico Villarreal". - RHist, 40 (1951), $187-195$.

10289. Service, Elman R. - "The encomienda in Paraguay". - HAHR, $3^{1}$ (1951), 230-252.

1029o. Mateos, F. - "La guerra guaranitica y las misiones del Paraguay. Segunda campaña $\left(1755^{-1756) " . ~-~ M H ; ~} 9\right.$ (1952), 75-121.

10291. Donoso, R. - "Aspectos de la producción histórica Chilena en los últimos diez años". - RIB, 1 (1951), 95-100. 10292. INGENIEROS, José-Evolución de las ideas argentinas. - Atenco, Buenos Aires, 1951. 2 ts.: 618 y 609 pp.

10293. Veiga, Gláucio - "Kant e o Brasil". - RBF, 1 (1951), 86-97.

10294. LiNs, Ivan - "Primeiros contactos brasileiros com Augusto Comte". $R B F, 2$ (1952), 77-83.

V. también núm. 10611 .

\section{HISPANISMO Y VIAJES DE EXTRANJEROS}

10295. Wright, Irene A. (ed.) - Further English voyages to Spanish America, 1583-1594. Published for the Hakluyt Society. - Quaritch, London, 1951. xciii $+3^{14}$ pp. 
10296. Rowse, A. L. - Sobre: I. A. Wright, Further English voyages to Spanish America. - Engl. Histor. Rev$i e w, 67$ (1952), 267-268.

10297. X. - Sobre: I. A. Wright, Further English voyages to Spanish America. $T L S, 25$ de enero de 1952, p. 74.

10298. Frrmor, Patrick Leigh - Viaje a través de las Antillas. - Labor, Barcelona, s. a. $47^{\circ} \mathrm{pp}$.

10299. KISCH, EGON E. - Entdeckungen in Mexiko. - Aufbau-Verlag, Berlin, 1951. $324 \mathrm{pp}$.

10300. Helfritz, Hans - Chile, gesegnetes Andenland. - Fretz und Wasmuth, Zürich, [1951]. 334 pp. + go láms.

V. también núms. $10157,10472$.

\section{PALEOGRAFAa, DIPLOMÁTICA, TEX. TOS, CRITICA TEXTUAL, CIENCIAS AUXILIARES}

10301. Goñi Gaztambide, Jost - "Notas sobre la Biblioteca capitular de Pamplona en la Edad Media". - HS, 4 (1951), núm. 8.

10302. VIves, J. - "Manuscritos hispánicos en bibliotecas extranjeras". - $H S$, 4 (1951), 467-475. [Bibliotecas de Göttingen y Stuttgart]. - V. núms. 5466 y $775^{\circ}$.

10303. Llamas, JosE - Biblia medieval romanceada judio-cristiana. T. 1: Génesis-Reyes. - C. S. I. S., Madrid, $195^{\circ}$.

10go4. Salomonski, Eva - Sobre: José Llamas, Biblia medieval romanceada judio-cristiana, t. 1. - VoxR, 12 (195152), $184-185$.

10305. Cordoliani, A. - "Los textos y figuras de cómputo de los códices Aemilianensis y el Tratado del cómputo de Rodríguez Campomanes". - $R B D, 5$ (1951), $117^{-152 .}$

10go6. Tilander, Gunnar (ed.) - Los fue ros de la Novenera. - Stockholm, 1951. 237 pp. (Leges Hispanicae Medii Aevi, 2).

10307. B[ERTINI], G. M. - Sobre: Los fue. ros de la Novenera, ed. G. Tilander. QIA, 2 (1952), $210-211$.

10308. Ercock, W. D. - Sobre: Los fueros de la Novenera, ed. Gunnar Tilander. - $M L R, 4^{8}$ (1953), 88 p.

10gog. Henry, A. - Sobre: Los fueros de la Novenera, ed. G. Tilander. $-R B P H$, $3^{\circ}\left(195^{2}\right), 5^{62}$.

10310. Lear, F. S. - Sobre: Los fueros de la Novenera, ed. G. Tilander. $-S p, 27$ (1952), 429-431.

10311. López EsTrada, F. - Sobre: Los fueros de la Novenera, ed. G. Tilander. - AUH, 12 (1951), núm. 3, 69-7o.

10312. Moldenhauer, G. - Sobre: Los fueros de la Novenera, ed. G. Tilander. - Fil, 3 (1951), 223-227.

10g13. Mourin, L. - Sobre: Los fueros de la Novenera, ed. G. Tilander. Scriptorium, 6 (1952), 168.

10314. Pottier, B. - Sobre: Los fueros de la Novenera, ed. G. Tilander. - AIL, 5 (1952), 379-382.

10315. Rohlfs, G. - Sobre: Los fueros de la Novenera, ed. G. Tilander. - ASNS, 189 (1952), 93-94.

10316. SNEYders DE VOGel, K. - Sobre: Los fueros de la Novenera, ed. G. Tilander. $-N, 3^{6}$ (1952), $186-187$.

10317. Ynduráin, F. - Sobre: Los fueros de la Novenera, ed. G. Tilander. $R F E, 36$ (1952), $145^{-14} 6$.

10318. Moldenhauer, G. - Sobre: $E l$ fuero de Teruel, ed. M. Gorosch.-AIL, 5 (1952), 382-388.

10319. Mallon, J. - Paléographie romaine. - C. S. I. C., Madrid, 1952. 188 pp., ilustr.

1032o. Gómez del Campillo, M. - “De cifras". - Sep. de $B A H, 129$ (1951). $35 \mathrm{pp}$.

10321. Mallon, J., y T. Marfin - Las inscripciones publicadas por el Marqués de Monsalud (1897-1908). Estudio critico. - C. S. I. C., Madrid, 1951. xxvii + $15^{1}$ pp., ilustr.

10322. D'Ors, Alvaro - Sobre: J. Mallon y T. Marín, Las inscripciones publicadas por el Marqués de Monsalud (I8971908); y J. Mallon, Paléographie romaine. - Arb, 25 (1953), 130-135.

V. también núm, 10214 .

\section{LINGÜISTICA}

\section{OBRAS GENERALES}

10323. Bibliographie linguistique de l'année 1949 et complément des années précedentes. - C.I.P.L., Spectrum, UtrechtAnvers, 1951 . xxiv +283 pp. - V. núm. 7759 .

10g24. Knower, Franklin H. - "A selected bibliography of bibliographies for students of speech". - South. Speech Journ., 17 (1951), 141-153.

10325. Tharp, James B. - Annotated bibliographies of modern language methodology for the years 1946, 1947 , 1948. - Ohio State Univ., Columbus, 1952. $\mathrm{x}+74 \mathrm{pp}$.

10326. Tharp, J. B. - "Annotated bibliography of modern language meth- 
odology for 1949". - MLJ, 35 (1951), 53-70. - V. núm. 10325 .

10327. Hall, Robert A., Jr. - "American linguistics, 1925-1950". - $A L, 3$ (1951), 101-125; 4 (1952), 1-16.

10328. Marouzeau, J. - Lexique de la terminologie linguistique, français, allemand, anglais, italien. $3^{\mathrm{e}}$ éd. $-\mathrm{P}$. Geuthner, Paris, 1951. xii + 265 pp.

10329. NiedermanN, Max - Sobre: J. Marouzeau, Lexique de la terminologie linguistique. - VoxR, 13 (1953), 103113 .

10330. Chaves de Melo, Gladstone, e Serafim Silva Neto - Conceito e método da filologia. Pról. de Sousa da Silveira.Organização Simões, Rio de Janeiro, 1951. $92 \mathrm{pp}$.

10331. Cohen, Marcel - Questionnaire linguistique. Publié par le Comité International Permanent des Linguistes.Het Spectrum, Utrecht, 1951-52.

10332. Rapport sur l'activité du Cercle de linguistique de Copenhague, 1931-195I. - Nordisk Sprog- og Kulturforlag, Copenhague, 1951. $67 \mathrm{pp}$.

\section{Teoría del lenguaje}

10333. Tagliavini, Carlo - Introduzione alla glottologia. $4^{\text {a }}$ ed. - R. Pàtron, Bologna, 1950. 506 pp.

10334. T[Ovar], A. - Sobre: C. Tagliavini, Introduzione alla glottologia. $4^{\text {a }}$ ed. $-E m, 20$ (1952), 527-528.

10335. Ammann, HermanN - Sobre: W. Porzig, Das Wunder der Sprache. $-R F$, $64\left(195^{2}\right), 147 \cdot 15^{6}$.

10336. Bucca, Salvador - Sobre: W. Porzig, Das Wunder der Sprache. AIL, 5 (1952), 342-345.

10337. DeutschmanN, Olaf - Sobre: W. Porzig, Das Wunder der Sprache. - RJ, 4 (1951) [publ. 1952], 395-398.

10338. JABERG, K. - Sobre: W. Porzig, Das Wunder der Sprache. - VoxR, 13 (1953), 100-103.

10339. Weisgerber, Leo - Das Gesetz der Sprache als Grundlage des Sprach. studiums. - Quelle und Meyer, Heidelberg, 1951. $201 \mathrm{pp}$.

10340. Gerathewohl, FrTt-Die Sprache als Lebenserscheinung. - Kerle, Heidelberg, 1950. $139 \mathrm{pp}$.

10341. BERTOLDI, V. - La storicità dei fatti di lingua. Nuovi mezzi e metodi atti a valutarla. - Liguori, Napoli, 1951. 143 pp.

10342. Meader, Clarence L., \& J. H. MUYSKENS - Handbook of biolinguistics. Part I, Section A: The structures and processes of expression with general introduction to biolinguistics. H. C. Weller, Toledo (Ohio), $195^{\circ}$. $\mathrm{xxi}+330 \mathrm{pp}$.

10343. Trojan, Felix - Sprachrhythmus und vegetatives Nervensystem. - Sexl, Wien-Meisenheim, 1951.

10344. Cassirer, ERnst - Language and myth. Trans. by S. K. Langer. - Dover Publs., New York, 1946. 114 pp.

10345. Clardo, Manlio - "Mito dell'infanzia e poesia". - $L M, 3$ (1952), 674683. [El sistema de Vico].

10346. O'Connor, D. J. - "Philosophy and ordinary language". - $J P h, 4^{8}$ (1951), 797-808.

10347. Heaths, P. L. - "The appeal to ordinary language". - PhiQ, 2 (1952), 1-12.

10348. Schiaffini, Alfredo-"El lenguaje en la estética de Croce". - NRFH, 7 (1953), 17-22.

10349. Wells, Rulon S. - "De Saussure's system of linguistics". - Word, 3 (1947), núms. 1-2.

1035o. Stalin, J. - Der Marxismus und die Fragen der Sprachwissenschaft. Dietz, Berlin, 1951. 65 pp.

10351. MarkiewICZ, H.-O marksistowskiej teorii literatury. - Wróclaw, $195^{2}$. $126 \mathrm{pp}$.

10352. MURRa, J. V.; R. M. HANKin; F. Holling (transl.) - The Soviet linguistics controversy. Transl. from the Soviet press. - King's Crown Press, New York, 1951. vi $+9^{8} \mathrm{pp}$.

\section{Estudios lingüísticos generales}

10353. Forchhammer, Jörgen - Die Aus. bildung der Sprechstimme auf stimm. und sprechwissenschaftlicher Grundlage. $3^{\text {a }}$ ed. - Hueber, München, 1951. viii $+92 \mathrm{pp}$.

10354. Malone, KeMp - Sobre: R.-M. S. Heffner, General phonetics. - $M L N$, 68 (1953), 38.42.

10355. Gimson, A. C. - Sobre: R. M. S. Heffner, General phonetics. - MLR, 47 (1952), 96-97.

10356. Jakobson, Roman - "On the proper treatment of phonemic problems".$S, 5$ (1951), 328-336.

10357. BOLINGER, D. L. - "Intonation: levels versus configurations". - Word, 7 (1951), núm. 3 .

10358. Entwistle, William J. - Sobre: R. H. Robins, Ancient and mediaeval grammatical theory in Europe. - MLR, 47 (1952), $5^{61-562 .}$

10359. Hoenigswald, Henry M. - Sobre: 
R. H. Robins, Ancient and mediaeval grammatical theory in Europe. - Lan, 29 (1953), 180-182.

10360. PotTer, S. - Sobre: R. H. Robins, Ancient and mediaeval grammatical theory in Europe. - ES, 33 (1952), fasc. 5 -6.

10361. Meriggi, P. - Sobre: Moritz Regula, Grundlegung und Grundprobleme der Syntax. $-R J, 4$ (1951) [publ. 1952], 422-424.

10362. Twadell, W. F. - Sobre: Moritz Regula, Grundlegung und Grundprobleme der Syntax. - Lan, 28 (1952), $112-113$.

10363. Sprtzer, Leo - "Sur quelques emplois métaphoriques de l'impératif: un chapitre de syntaxe comparative". Ro, 72 (1951), 433-478; 73 (1952), 16-63. 10364 . Deutschmann, Olaf - Sobre: Kurt Baldinger, Kollektivsuffixe und Kollektivbegriff. - RJ, 4 (1951) [publ. 1952], 398-408.

10365. PieL, JosepH M. - Sobre: Kurt Baldinger, Kollektivsuffixe und Kollektivbegriff. - RF, 64 (1952), 166-168. 10366. Ullmann, Stephen - The principles of semantics. - Jackson, Glasgow, 1951. 314 pp.

10367. GILL, AUSTIN - Sobre: S. Ullmann, The principles of semantics. $M L R, 4^{8}$ (1953), 207-209.

10368. GougenHeIM, G. - Sobre: S. Ullmann; The principles of semantics. FrM, 20 (1952), 148-150.

10369. Werner, Heinz - Sobre: S. Ullmann, The principles of semantics. Lan, 28 (1952), 249-256.

10370. Ullmann, S. - Précis de sémantique française. - Francke, Berne, 1952. 334 pp. (Bibliotheca Romanica, I, 11).

10371. Robson, C. A. - Sobre: S. Ullmann, Précis de sémantique française. $-F S, 7$ (1953), $185-187$.

10372. Gougenheim, Georges - "Points de vue nouveaux en sémantique". Crit, 9 (1953), 429-437. [Sobre: S. Ullmann, The principles of semantics $y$ Précis de sémantique française].

10373. ÖHMANN, SuzANNE - Wortinhalt und Weltbild. Vergleich. $u$. methodol. Studien zur Bedeutungslehre und Wortfeldtheorie. - Norstedt, Stockholm, 1951. 194 pp.

10374. Battaglia, O.F. DE - Sobre: J. Casares, Introducción a la lexicogra. fia moderna. - Era, 5 (1952), núms. $7-8$.

10375. IAnnucci, James E. - Sobre: J.
Casares, Introducción a la lexicografia moderna. - HR, 20 (1952), 265-266.

10376. Monge, Félix - Sobre: J. Casares, Introducción a la lexicografia moderna. - Arb, 18 (1951), 158-159.

10377. BerTOLDI, VITTORIO - L'arte dell'etimologia. - Liguori, Napoli, 1952.

10378. Juret, A. - "Formation des idées étudiée au moyen de l'étymologie: groupe sémantique de la 'limite" RLiR, 17 (1951), núms. 65-66.

10379. JABERG, KARI. - "Krankheitsnamen. Metaphorik und Dämonie". Schweizer Archiv für Volkskunde, 47 (1951), 77-113.

10380. Vidos, B. E. - "Mots créés, mots empruntés et curiosités lexicologiques". - RPF, 4 (1951), 269-3og.

10381. Bertoldi, Virrorio - "Metodi vecchi e nuovi nella ricerca etimologica”. - Sep. de AGIt, $3^{6}$ (1951), núm. 1. $4^{8} \mathrm{pp}$.

10382. Troisième Congrès International de toponymie et d'anthroponymie, Bruxelles, juillet 1949. - Louvain, $195^{1}$. T. 1: Programme, 100 pp.; ts. 2-3, Actes et mémoires, 856 pp.

10383. Burks, A. W. - "A theory of proper names".-Philosophical Studies, 2 (1951), $3^{6-45}$.

10384. Doppagne, Albert - "Contribution méthodologique à l'étude des prénoms". - Troisième Congrès Intern. de top. et d'anthr. (Louvain, 1951), 3, $700-715$.

10385. Meertens, Pieter - "L'importance de l'anthroponymie pour l'histoire ecclésiastique". - Troisième Congrès Intern. de top. et d'anthr. (Louvain, 1951), 3, 716-721.

10386. KNUdsen, GunNar - "Personalnames dictionaries". - Troisième Congrès Intern. de top. et d'anthr. (Louvain, 1951), 3, 696-699.

10987. POKORNX, J. - "Zu keltischen Namen". - BzN, 2 (1950-51), 33-39, $247^{-2} 5^{1} ; 3$ (1951-52), 89-92, 208-211.

10388. Dauzat, Albert - Dictionnaire étymologique des noms de famille et prénoms de la France. - Libr. Larousse, Paris, 1951. xii +604 pp.

10389. PAWLIK, P. - "Toponomastik, Ethnologie und Geographie". - Troisième Congrès Intern. de top. et d'anthr. (Louvain, 1951), 3, 375-393.

1039o. Skok, PIERre - "La linguistique de Ferdinand de Saussure et la toponymie". - Troisième Congrès Inter. 
de top. et d'anthr. (Louvain, 1951), 2, $125-132$.

10391. Mansuelli, G. A. - “Topografia storica. Le provincie occidentali del mondo antico (Hispaniae, Galliae, Germaniae, Raetiae, Noricum)". - Doxa, 4 (1951), 54-75- 97-120.

10392. KRAHE, H. - "Alteuropäische Flussnamen". - BzN, 2 (1950-51), 113$131,217-237 ; 3$ (1951-52), 1-18, 153-170, $225^{-243}$.

10393. Terracini, Benvenuto - "Parentesco lingüístico. (Contribución a la historia de un concepto)". - NRFH, 7 (1953), 23-33.

10394. Pisani, V. - "Parenté linguistique”. - Lingua, 3 (1952), 1-16.

10395. Deanović, Mirko - "Perché è spinoso il problema dei confini linguistici". - Orbis, 2 (1953), 297-301.

\section{LENGUAS INDOEUROPEAS}

10396. Mayrhofer, MaNfred - Handbuch des Pali. - Winter, Heidelberg, $195^{1 .}$ 2 ts.: 214 y 83 pp. (Indogermanische Bibliothek).

10397. R[onríguez] Adrados, F. - Sobre: M. Mayrhofer, Handbuch des Pali. Em, 20 (1952), 540-542.

10398. Tovar, Antonio (ed.) - Manual de lingüistica indoeuropea. - C.S.I.C., Madrid, 1947-1952. 14 cuadernos.

10399. KRAHE, H. - Sprachverwandtschaft im alten Europa. - Winter, Heidelberg, 1951. 30 pp.

10400. R[ODRf́GUEz] AdRADOs, F. - Sobre: H. Krahe, Sprachverwandtschaft im alten Europa. - Em, 20 (1952), 528530.

10401. Deeters, G. - Sobre: C. D. Buck, $A$ dictionary of selected synonyms in the principal Indo-European languages. - Indogermanische Forschungen, 61 (1952), núm. 1.

10402. Hall, Robert A., JR. - Sobre: C. D. Buck, A dictionary of selected synonyms in the principal indo-European languages. - VoxR, 12 (195152), 361-364.

10403. Wersgerber, L. - Sobre: C. D. Buck, $A$ dictionary of Indoeuropean synonyms. - Gnomon, 24 (1952), núm. 4 .

10404. Benveniste, E. - "Prétérit et optatif en indo-européen". - BSLP, 47 (1951).

$1040_{5}^{5}$. Pokorny, Julius - Indogermanisches etymologisches Wörterbuch. Fasc. 1-7 (a- leizd-), pp. 1-672. - Francke, Bern, 1950-53.
10406. T[OVAR], A. - Sobre: J. Pokorny, Indogermanisches etymologisches Wörterbuch. - Em, 20 (1952), 173-174.

10407. Vendryes, J. - Sobre: J. Pokorny, Indogermanisches Etymologisches Wörterbuch. - VoxR, $12\left(195^{1-52}\right), 181$ 184 .

10408. Whatmough, Joshua - Sobre: J. Pokorny, Indogermanisches etymologi. sches Wörterbuch. - Lan, 29 (1953), 481-483. - V. núm. $84 i^{1}$.

V. también núms. $\log _{3} 87,10392$.

\section{LATÍN Y LENGUAS PRERROMÁNICAS}

10409. Devoto, Giacomo - Gli antichi Italici. $2^{\text {a }}$ ed. - Vallecchi, Firenze, 1951. $35^{6}$ pp. (Collana Storica, 29).

10410. Whatmough, J. - Sobre: G. Devoto, Gli antichi Italici. - Lan, 29 (1953), 19o-192.

10411. Altheim, Fr. - Der Ursprung der Etrusker. - Verlag für Kunst und Wissenschaft, Baden-Baden, 1950. $7^{2}$ pp.

10412. Carnoy, A. - "La langue étrusque et ses origines". - $A C, 21$ (1952), núm. 2.

10413. Beeler, M. S. - Sobre: J. Hubschmid, Praeromanica. - RomPh, 7 (1953-54), $77^{-80}$.

10414. WAgner, M. L. - Sobre: J. Hubschmid, Praeromanica. - VoxR, 12 (1951-52), 364-369.

10415. FEIST, SIGMUNd - Germanen und Kelten in der antiken Ueberlieferung. - Verlag für Kunst und Wissenschaften, Baden-Baden, 1948. iv +75 pp. (Neue Germanenforschungen, 1).

10416. Palomar Lapesa, M. - Sobre: S Feist, Germanen und Kelten in der antiken Ueberlieferung. - Em, 20 (1952), $542-545$.

10417. WALde, AloIs - Lateinisches etymologisches Wörterbuch. 3. neuarb. Aufl. von J. B. Hofmann. Fasc. 16-19 [t. 2, pp. 353-672]. - C Winter, Heidelberg, $1950-52$. - V. núm. 6471 .

10418. HoFmANN, J. B. - Lateinische Umgangsprache. $3^{\text {a }}$ ed. - Carl Winter, Heidelberg, $195^{1}$. xvi $+212 \mathrm{pp}$.

10419. Díaz-Regañón, J. M. - "Nuevas ideas sobre fonética y morfologia latina". - Sait, 10 (1950-1951), 175-181. [Sobre: A. Pariente, Estudios de fonética y morfologia latina].

10420. Hanssen, J. S. Th. - Latin diminutives. A semantic study. - John Griegs Boktrykkeri, Bergen, 1951. 266 pp. 
10421. AmmanN, H. - "Zu lat. quisquis es". - Indogermanische Forschungen, 60 (1949), núm. 1.

10422. Josserand, CH. - Sobre: J. André, Étude sur les termes de couleur dans la langue latine. - RBPH, 29 (1951), 1213-1215.

10423. Miniconi, Pierre Jean - "Causa" et ses dérivés. Contribution à l'étude historique du vocabulaire latin. Paris, 1951. 211 pp.

10424. Ernout, A. - Sobre: J. P. Miniconi, "Causa" et ses dérivés. - RevPh, 26 (1952), 242-243.

10425. SANTONU, ANTONIA - L'elemento latino nell' idronomastica della Sardegna. - Facoltà di Lettere e Filosofia dell' Università, Cagliari, $195^{1}$. xliii +510 pp.

10426. Niedermann, Max - Sobre: G. Rohlfs, Sermo vulgaris latinus. VoxR, 12 (1951-52), 375-383.

10427. Souter, Alexander - A glossary of later Latin to 600 a. D. - Clarendon Press, Oxford, 1949. xxxii + 454 pp. 10428. NiedermanN, Max - Sobre: A. Souter, $A$ glossary of later Latin to 600 a. D. - VoxR, $12\left(195^{1-52}\right), 369-$ 375 .

10429. Mohrmann, Christine - "Le dualisme de la latinité médiévale". $R E L, 29,330-348$.

V. también núms. 10548-56, 10620, 10623 .

\section{FILOLOGIA ROMÃNICA}

10430. Storost, J. - “Zur Geschichte der romanischen Philologie. Karl Voretzsch (1867-1947)". - Wiss, Zeitschrift der Univ. Greifswald, 1 (1951-1952), 58-69.

10431. Hall, Robert A., JR. - [Jakob Jud, In memoriam]. Lan, 29 (1953), 104-105.

10432. Herculano de Carvalho, José G. C. - "Jakob Jud. In memoriam". $R P F, 5\left(195^{2}\right), 499-501$.

10433. HubER, KonRAD - “Jakob Jud zum Gedächtnis”. - ASNS, 189 (1952), 331-333.

10434. HUbSchmied, J. U. - "Jakob Jud". - $O n, 3$ (1952), 81-83.

10435. M[IGLIORINI], B. - "Jacob Jud". $L N, 13$ (1952), 94-95.

10436. Patva Bolko, Manuel De - "O exemplo de um grande mestre”. [Jakob Jud], - RPF, 5 (1952), 501-507.

10437. Pop, Sever - "Jakob Jud". Orbis, 1 (1952), 570-575.

10438. Steiger, A. - "In memoriam Ja- kob Jud". - VoxR, $12\left(195^{1-52), ~ p p . ~}\right.$ ix-xix.

10439. X. - "Die romanistischen Dissertationen seit 1945 an deutschen Universitäten angenommene, nicht im Druck erschienene Doktorarbeiten". $R J, 4$ (1951) [publ. 1952], 43-61.

1044o. Hakamies, Reino - "Bibliographie de la philologie romane en Finlande depuis 1938". - RJ; 4 (1951) [publ. 1952], 144-159.

10441. TögebY, K. - “La linguistique romane au Danemark (1939-1945)". RLiR, 17 (1951), núms. 65-66.

10442. Sofer, J. - "Die Differenzierung der romanischen Sprachen". - $s p r, 2$ (1951), fasc. 1 .

10443. Kahane, Henry R. - Sobre: Alwin Kuhn, Romanische Philologie, I. - RomPh, 6 (1952-53), 313-314.

10444. LeVy, Raphael-Sobre: A. Kuhn, Romanische Philologie, I. - MLN, 68 (1953), 202-204.

10445. Malkiel, Yakov - Sobre: A. Kuhn, Romanische Philologie, I. Lan, 28 (1952), 509-525.

10446. Sobejano, Gonzalo - Sobre: A. Kuhn, Romanische Philologie, I. RFE, 36 (1952), 131-136.

10447. Maurer, Th. H. $-A$ unidade da România ocidental. - Univ. de São Paulo, 1951. 227 pp.

10448. Hall, Robert A., Jr. - Sobre: Th. H. Maurer, $A$ unidade da Románia ocidental. - Lan, 29 (1963), 530532.

10449. Vossler, KARL - Die romanischen Kulturen und der deutsche Geist. Mit einer Einführung von Benedetto Croce und einem Nachwort von H. Friedrich. - Ernst Klett, Stuttgart, 1948. $77 \mathrm{pp}$.

10450. Ostermann, Theodor - Bibliographie der Schriften von Karl Vossler 1897-1951. - Bayr. Akad. der Wissenschaften, München, 1951. $92 \mathrm{pP}$.

1045̆1. Bertoldr, V. - “Alusiones geográficas en términos de la técnica y del mercado". - NRFH, 7 (1953), 63. 72.

10452. Bertoldi, V. - "Nuove valutazioni storiche di vecchi termini tecnici”. - ZRPh, 68 (1952), núm. 1-2.

10453. Whatmough, Joshua - Sobre: V. Bertoldi, Colonizzazioni nell'antico $\mathrm{Me}$ diterraneo Occidentale alla luce degli aspetti linguistici. - Lan, 28 (1952), $525-527$.

10454. Menéndez Pidal, R. - "Sufijos 
átonos en el Mediterráneo occidental'. - NRFH, 7 (1953), 34-55.

10455. Alessio, G. - "Problemi di etimologia romanza". - RLiR, 17 (1951), núms. $65-66$.

10456. PISANI, V. - "Scorrerie nel campo dell'etimologia romanza”. - Ann. della Fac. di Lettere dell'Univ. di Cagliari, 18 (1951), 383-398.

10457. Terracini, Lore-Sobre: B. Maler, Synonymes romans de l'interrogatif "qualis". - RomPh, 7 (1954), 348-354. 10458. Aebischer, Paul - "Les dénominations des 'céréales', du 'blé' et du 'froment' d'après les données du latin médiéval. Étude de stratigraphie linguistique". - EPM, 1951, núm. 129, 77-94.

10459. Malkiel, YaKov - "Graeco-latin iudaeus and iudaicus in the Romance languages". - SOS, 11 (1951), 327-338. 10460. SEIfert, EVA - Sobre: Anna Lichtenhahn, La storia di "ove", "dove", "onde", "donde" ... - RF, 64 (1952), $172-176$.

10461. ElCock, W. D. - "Quelques survivances de tenuis". - EPM, 1951, núm. 129, 161-171.

10462. SORrento, Luigr - Sintassi romanza. $2^{\text {a }}$ ed. - Cisalpino, Milano, 1951. $420 \mathrm{pp}$.

10463. Rohlfs, G. - Sobre: L. Sorrento, Sintassi romanza. - ASNS, ${ }_{1} 89$ (1952), p. 382 .

10464. Taylor, George Benjamin Verbal aspect in early Romance. [Tesis de la Universidad de Stanford, 1951 .

10465. Prati, ANGelico - Vocabolario etimologico italiano. - Garzanti, Torino, 1951. xii +1097 pp.

10466. Rohlfs, G, - Sobre: A. Prati, Vocabolario etimologico italiano. - ASNS, 189 (1952), 413.414.

10467. WAGNER, MAX LEOPOLD - La lin. gua sarda; storia, spirito e forma. - A. Francke, Bern, [1951]. $4^{16}$ pp. (Bibliotheca Romanica).

10468. Hall, ROBERT A. Jr. - Sobre: M. L. Wagner, La lingua sarda. - RomPh, 6 (1952-53), 203-205.

V. también núms. 10391, 10612.

\section{FILOLOGIA HISPÁNICA}

10469. SPinelli, Vincenzo - "Sentimento delle lingue iberiche. Saggio di una nuova interpretazione dei fatti linguistici". - Criterion (Minas Gerais, Brasil), 4 (19501), 131-145. 1047o. Hämel, Adalbert - "Hispanistische Studien in Spanien (19391949)". - GRM, 1 (1951), $218-290$.

10471. Smither, William J. - Doctoral theses in the Hispanic languages and literatures, 1951". - HispB, 35 (1952), 173-178. - V. núm. 8394

10472. HÄмeL, A. - "Ludwig Pfandl". Clav, 1951, núm. 12, 4-8.

10473. Duncan, R. M. - Sobre: Amado Alonso, Estudios lingüisticos: temas españoles. $-S, 7$ (1953), 181-186.

10474. Rohlfs, G. - Sobre: A. Alonso, Estudios lingüisticos. Temas españoles - ASNS, 189 (1952), p. 398.

10475. B[ARrenecheA], A. M. - "Bibliografía de Amado Alonso". [Addenda].$B A L, 195^{2}$, núm. 1, 8-10. - V. núm. 695 .

10476. "Bibliografía de Amado Alonso".NRFH, 7 (1953), 3-15.

10477. A[Lonso], D. - "Amado Alonso (1896-1952)". - RFE, $3^{6}$ (1952), 204208.

10478. Alonso, D. - "Amado Alonso ante la muerte”. - Ins, 7 (1952), núm. 78 . 10479. Arce DE Blanco, Margot - "Amado Alonso". - Asom, 1952, núm. 4, pp. $5^{-6 .}$

10480. [BARRENECHEA, ANA MARÍA] "Amado Alonso". - BAL, 1952, núm. 1, $1-2$.

10481. B[ataillon], M. - "Amado Alonso". - BHi, 54 (1952), $45^{\circ-45^{2}}$.

10482. B[ERTINI], G. M. - "In memoriam: Amado Alonso". - QIA, 2 (1953), 261262.

10483. C[ANo], J. L. - "Una gran pérdida: Amado Alonso". - $\mathrm{CuH}, 11$ (1952), 271-273.

10484. Carmlla, Emilo - "Amado Alonso, en la Argentina”. - $\mathrm{CuH}, 18$ (1954), 368-376.

10485. Cisneros, Luis Jaime - "Amado Alonso". - MdS, 1952, núm. 21, p. 86. 10486. Clavería, Carlos - "Amado Alonso (1896-1952)". - HR, 20 (1952), 332333 .

10487. García Blanco, M. - "Amado Alonso". - On, 3 (1952), 78-80.

10488. LAPESA, RAFAEL - "Amado Alonso (1896-1952)". - HispB, 36 (1953), $145^{-147}$

10489. L[IDA], R[AIMUNDo] - "Amado Alonso (1896-1952)". - NRFH, 6 (1952), 205-208.

1049o. Lida [De Malkiel.], María Rosa "Amado Alonso" - Ins, 7 (1952), núm. $7^{8}$ [Reproducción de la "Semblanza" puesta al frente de la Biblio. 
grafia de Amado Alonso, Buenos Aires, $194^{6]}$.

10491. Mendez Plancarte, Alfonso "Rosas sobre la tumba de Amado Alonso". - A bs, 17 (1953), 239-249.

10492. Menéndez Pidal, Ramón - "Amado Alonso". - Ins, 7 (1952), núm. $7^{8}$.

10493. OCAMPO, VICTORIA - "Amado Alonso". - Sur, 1952, núms. 211/2, 124 ss.

10494. Pérez Delgado, G. S. - "Elogio de Amado Alonso". - EstA, 5 (1953), 37-43.

10495. Reyes, Alfonso - "Amado Alonso". - NRFH, 7 (1953), 1-2.

10496. Rodrfguez Monegal, Emir - "La estilística de Amado Alonso". - Núm, 4 (1952), 321-332.

10497. Rosenblat, ANGel - "Amado Alonso". - CU, 1952, núm. 31, 61-71.

10498. Rosenblat, Ángel - "Amado Alonso". - CurCon, 43 (1953), $113-119$.

10499. R[IVAs] S[ACCONI, J. M.] - "Amado Alonso"; "Amado Alonso y Thesaurus". - BICC, 8 (1952), 286-289.

10500. Terracini, Benvenuto - "In memoria di Amado Alonso". - Sep. de AGIt, 37 (1952), núm. 2. 8 pp.

10501. X. - “Un estilo de vida". - Núm, 4 (1952), 297-298. [Sobre Amado Alonso].

10502. X. - "Amado Alonso". - CurCon, 41 (1952), 97-98.

V. también núms. 10090-91.

\section{CATALÃN Y VALENCIANO}

10503. Badía Margarit, A. - "Une nouvelle grammaire historique de la langue catalane". - Orbis, 2 (1953), 113-121. [La Gramática histórica catalana del mismo autor].

10504. A[LARcos] Ll[ORACH], E. - Sobre: A. Badía Margarit, Gramática histórica catalana. - AO, 2 (1952), 433-435.

10505. Frank, Istrín - Sobre: A. Badía Margarit, Gramática histórica catalana. - Ro, 74 (1953), 545-546.

105o6. Griera, A. - Sobre: A. Badía Margarit, Gramática histórica catalana. - BDE, 31 (1952), 53-58.

10507. Monge, Félix - Sobre: A. Badía Margarit, Gramática histórica catalana. - Arb, 23 (1952), 165-167.

10508. Rohlfs, G. - Sobre: A. Badía Margarit, Gramática histórica catalana. - ASNS, 190 (1953), p. 171.

10509. Guiter, H. - "Faits de fermeture vocalique dans quelques hautes vallées catalanes". - RLR, 71 .
10510. F. P. - Sobre: A. Griera, Atlas lingüistic de Catalunya, I-IV $-B D E$, 30 (1950-51), 63-66.

10511. Badfa Margarit, A. - "L'Atlas lingüistic de Catalunya i el problema de la sibilant sonora $-s$ - (fon. $z$ ), procedent del llatí -D- (i de -G-, -TY-)". $R V F, 2$ (1952), 7-32.

10512. Griera, A. - "Vocabulario catalán de origen eclesiástico". - $B D E$, $3^{\circ}$ (1950-51), 7-51.

10513. Griera, A.- "Les études de toponymie dans le domaine catalan".Troisième Congrès Internat. de top. et d'anthr. (Louvain, 1951), 2, 78-84. V. núm. 6084.

V. también núm. 10623 .

\section{GALLEGO Y PORTUGUES}

10514. Pires de Lima, A. C. - Estudos etnográficos, filológicos e históricos. Comissão de Etnografia e História, Pôrto, 1950. Ts. 5 y 6: 359 y 418 pp. - V. núm. 8527 .

10515. Krüger, F. - Sobre: A. C. Pires de Lima, Estudos etnográficos, filológi$\cos e$ históricos, ts. 5 y $6-B d F, 13$ (1952), 337-344. - V. núm. $85^{28}$.

10516. Silva Pereira, M. P. DA - Sobre: C. A. Pires de Lima, Estudos etnográficos, filológicos $e$ históricos, t. 5. $R P F, 5$ (1952), 297-305.

$105^{17}$. Kiddle, L. B. - Sobre: G. Manuppella, Os estudos de filologia portuguesa de 1930 a 1949: Subsidios bibliográficos. - Lan, 29 (1953), 540-541.

10518. Potrier, B. - Sobre: G. Manuppella, Os estudos de filologia portuguesa de r93o a r949. - BHi, 54 (1952), $435-437$.

10519. RÉvah, I. S. - Sobre: G. Manuppella, Os estudos de filologia portuguesa de 1930 a 1949. - BEPI, 15 (1951), 223-224.

10520. Torrinha, Francisco - "Nótulas filológicas". - Por, $3^{\text {a }}$ serie, 1 (19511952), núms. 1-2. - V. núm. 5040.

10521. Machado, José Pedro - "Influência arábica [na língua portuguesa]”.$R P, 16$ (1951) , 24-30, 49-53, 85-88, 118 $120,199-203$ y $219-222$.

10522. Nunes de Figuetredo, José - Elementos de gramática portuguesa. $14^{\mathrm{a}}$ ed. - Atlântida, Coimbra, 1951. 262 pp.

10523. Martins, Jứio - Abrégé de grammaire portugaise. $2^{\text {a }}$ ed. - Portugália, Lisboa. 144 pp.

10524. Moreno, Augusto - "Problemas de morfologia e sintaxe: A concordân- 
cia". - RP, 16 (1951), 31-33, 54-57, $89-93,121-125$ y $195^{-198}$. - V. núm. 4576 .

10525. Machado, José Pedro - "Questões etimológicas". - RP, 16 (1951), 322$326 ; 17$ (1952), 62-65, 87-94, 119-124, $147^{-1} 5^{2}, 19^{2-196}, 222-225,311-313$ y $335^{-}$ $337 ; 18$ (1953), 18-20.

10526. Chaves, Lufs - “Apontamentos de um português: Extensão de nomes de aprestos caseiros". - RP, 16 (1951), $69-71$.

1052\%. Machado, José Pedro - "A palavra 'árabe' e afins”. - RP, 16 (1951), 273-280.

10528. Carreiro da Costa, F. - "Etnografia agrícola. Alfaias agrícolas micaelenses". - Bol. da Comissão Reg. dos Cereais do Arquipélago dos Açores (Ponta Delgada), 1947-51, núms. 5-13.

10529. Carretro dA Costa, F. - Terminologia agricola micaelense. - Ponta Delgada, 1949, 62 pp.

10530. KrÜGER, F. - Sobre: F. Carreiro da Costa, "Etnografia agrícola. Alfaias agrícolas micaelenses"; Terminologia agricola micaelense; y $O$ tempo na linguagem popular micaelense. - AIL, 5 (1952), 419-422.

10531. J[UD], J. - Sobre: M. Palmira da Silva Pereira, A nespereira. Estudo linguistico. - VoxR, 13 (1953), 212.213.

10532. Chaves, Luís - "Anthroponymie et toponymie au Portugal".-Troisième Congrès Intern. de top. et d'anthr. (Louvain, 1951), 3, 729-736.

10533. Cunha Serra, Pedro - "Notas de toponímia. Malhada Sorda, Málhadas, etc." - Sep. de Labor, Aveiro (1951), núm. 114. $18 \mathrm{pp}$.

10534. Pop, Sever - Sobre: Visconde de Lagoa, Glossário toponímico da antiga historiografia portuguesa ultramarina. $-O n, 2$ (1951) , 59-6o.

10535. Delgado, Manuel Joaquim - $A$ linguagem popular do Baixo-Alentejo - Beja, 1951. 218 pp.

10536. KRügeR, F. - Sobre: M. J. Delgado, A linguagem popular do BaixoAlentejo, - BdF, 13 (1952), 327-336.

10537. Carvalho e Rego, Francisco de "O dialecto macaense".- $-R P, 16$ (1951), 3-7.

10538. Zamora Vicente, Alonso - "De geografía dialectal: $-a o$, -an en gallego". - NRFH, 7 (1953), $73^{-80}$.

10539. SPINELLI, VINCENZO-"Il portoghese del Portogallo ed il portoghese del Brasile nei loro particolari aspetti sonori".
Criterion (Minas Gerais, Brasil), 4 (1951), 293-303.

10540. Silveira Bueno - Tratado de semântica geral aplicada à lingua portuguesa do Brasil. $2^{\text {a }}$ ed., aum. - Saraiva, São Paulo, 1951. 239 pp.

10541. Lima, Hildebrando de, y Gustavo Barroso - Pequeno dicionário brasileiro da lingua portuguesa, $9^{\text {a }}$ ed. - Civilização Brasileira, Rio de Janeiro-São Paulo-Baia, 1951. xxxii + 1310 pp. V. $R F H$, núm. 5765 .

10542. Ayrosa, Plinio-Vocabulário português-brasilico - Universidade de São Paulo, São Paulo, 1951.

10543. Brown, Charles B., \& Milton L. Shane (compils.)-Brazilian Portuguese idiom list, selected on the basis of range and frequency of occurrence.-Vanderbilt Univ. Press, Nashville, 1951. xiii+ $118 \mathrm{pp}$.

10544. Buggehagen, E. A. von - Worteigentümlichkeiten der brasilianischen Sprache. - Inst. Hans Staden, São Paulo, 1951. 163 pp.

10545. Mortara, Giorgio - "Algunas observaciones sobre la asimilación lingüística de los inmigrantes del Brasil y de sus descendientes". - Boletin Informativo de la Fac. de Ciencias Económicas de Caracas, 3 (1951), núm. 10, $51-66$.

10546. Sá Nunes, José DE - "Nos dominios do tupi-guarani: A rotina e a caturrice". - RP, 16 (1951), 169-176. V. núm. 7921 .

10547. Seraine, Florival - Contribuição ao estudo da influência indígena no linguajar cearense". - Sep. de Rev. do Inst. do Ceará, 64 (195o), 16 pp.

V. también núm. 10634.

\section{VASCO}

10548. LAFON, R. - “Concordances morphologiques entre le basque et les langues caucasiques". - Word, 7 (1951), núm. 3 .

10549. T[Ovar], A. - "Sobre el vasco y el caucásico". - BSV, 6 (1950), 350-353. 10550. Lahovary, N. - "Affinités linguistiques basco-caucasiennes et balkaniques" - EJa, 5 (1951), núms. 3-6.

10551. BoudA, KarL - "Eine jüngst ermittelte archaische Sprachgruppe in Asien und Europa". - GRM, 32 (1951), 129-142. [Acerca de las semejanzas entre el caucásico y el vasco].

10552. Hubschmid, Johanes - "Das Baskische und der vorindogermanische topographische Wortschatz europäischer 
Sprachen". - Troisième Congrès Intern. de top. et d'anthr. (Louvain, 1951), 2, $183-19 \mathrm{I}$.

10553. Caro Baroja, Julto - "Les couches de la toponymie basque et le problème de la parenté des langues". - Troisième Congrès Intern. de top. et d'anthr. (Louvain, 1951), 2, 173-182.

10554. Casanovas Marques, L. - Sobre: N. M. Holmer, "Las relaciones vasco-celtas desde el punto de vista lingüístico". - Pir, 7 (1951), 641-642.

10555. Lahovary, N. - "Position linguistique du basque et du dravidien". RevIO, 3 (1951), 91-112. 185-198 y 275283.

10556. López Mendizábal, IsaAC-La lengua vasca. Gramática. Conversación. Diccionario vasco-castellano y castellano vasco. $2^{\text {a }}$ ed. - Edit. Vasca Ekin, Buenos Aires, 1949. 369 pp. (Biblioteca de cultura vasca).

10557. Giese, W. - Sobre: I. López Mendizábal, La lengua vasca. - AIL, 5 (1952), 378-379.

10558. Michelena, L. - "De fonética vasca. La aspiración intervocálica". $-B S V$, 6 (1950), 443.459.

10559. Casanovas Marques, L. - Sobre: L. Michelena, "De fonética vasca. La aspiración intervocálica". - Pir, 7 (1951), $642-643$.

\section{ESPAÑOL}

\section{Historia de la lengua}

1056o. Gillet, Joseph E. - "So la luna: notes on the life and death of a Spanish idiom". - Homenaje a A. M. Huntington (Wellesley, Mass., 1952), 193-2.17.

10561. Place, E. B.-Sobre: R. Menéndez Pidal, Origenes del español. - $S p, 28$ $\left(195^{2}\right), 110-111$.

1056.2. Atkinson, William C. - Sobre: V. García de Diego, Gramática histórica española. - BHS, 29 (1952), 167.

10563. González Ollé, F. - Sobre: V. Garcia de Diego, Gramática histórica española. - Arb, 24 (1953), 614-615.

10564. Lausberg, H. - Sobre: V. García de Diego, Gramática histórica española. $-R F, 6_{5}$ (1953), 171-172.

10565. Spaulding, Robert K. - Sobre: V. García de Diego, Gramática histórica española. - HR, 21 (1953), 252-258.

10566. London, Gardiner H. - Conjunctive adverbs in the prose texts of $\mathrm{Al}$ fonso $X$, the Learned. - [Tesis de la Univ. de Wisconsin, 1951].
10567. Roca Pons, J. - Sobre: P. Aebischer, Matériaux médiévaux por l'étude du suffixe d'origine germanique "ing" dans les langues de la péninsule ibérique. - Pir, 7 (1951), 640-641.

V. también núms. 10454, $10503-0810568$ $71,1060_{5}, 10659$.

\section{Fonética}

10568. Alonso, Amado - "O cecear ci. gano de Sevilla, 1540”. - RFE, $3^{6}$ (1952), I-5.

10569 . A[LARCOS] LI[ORACH], E. - Sobre: A. Alonso, Historia del ceceo y del seseo españoles. - $A O, 3,(1953), \mathbf{1}_{5}^{1}$ $15^{2 .}$

1057o. Corominas, Juan - Para la fecha del yeísmo y del lleísmo". - NRFH, 7 (1953), $81 \cdot 87$.

10571. Roca Pons, J. - Sobre: F. Lázaro Carreter, " $F>h$, ¿fenómeno ibérico o romance?" - Pir, 7 (1951), 638-639. 10572. Horrent, J. - "L'accentuation espagnole". - Sep. de Rev. des Langues Vivantes, 19, núm. 6. 20 pp.

10573. Canfield, D. Lincoln - "Andalu. cismos en la pronunciación salvadoreña". - HispB, 36 (1953), 32-33.

10574. Boyd-Bowman, Peter - "Sobre la pronunciación del español en el Ecuador". - NRFH, 7 (1953), $221-233$.

V. también núms. 10354-57, 10511,10559 , $10642-43$.

\section{Gramática \\ Morfología y sintaxis}

10575. Memoria del Primer Congreso de Academias de la Lengua Española ce. lebrado en México del 23 de abril al 6 de mayo de 1951. - Jus, México, $195^{2}$. $553 \mathrm{pp}$.

10576. Bolinger, Dwight L. - Sobre: S. Fernández, Gramática española, t. 1. -RomPh, 7 (1953-54), 209-215.

10577. Huarte, Fernando - Sobre: E. Alarcos Llorach, Gramática estructural. - RFE, $3^{6}$ (1952) , 353-355.

10578. Hesse, Everft W. - Spanish review grammar. Enlarged ed. - American Book Co., New York, 19522. vii +179 pp.

10579. Patín Maceo, Manuel A. - "Notas gramaticales" (cont.) - - BADL, 8 (1948), a 12 (1952), núms. 29-42.

10580. Rosenblat, ANGel - "Género de los sustantivos en - $e$ y en consonante". - EMP, 3, 159-202.

10581. Rosenblat, Ánget - "E1 género 
de los compuestos". - NRFH, 7 (1953), 95-112.

10 82 . Silverman, Joseph H. - Sobre: A. Rosenblat, Vacilaciones de género en los monosilabos. - RomPh, 7 (1953 54), $205-209$.

10583. Murphy, Spencer L., JR. - Sobre: E. Rodriguez Herrera, Observaciones acerca del género de los nombres. HispB, 36 (1953) , 250-252.

10584 . Casares, - J. - "Problemas de prosodia y ortografía en el Diccionario y en la Gramática". - $B A E, 31$ (1951), 369-453; 32 (1952), 7-26.

10585. Paratore, Axgela - Spanish aerb phrase and clause structure. - [Tesis de la Univ. de Cornell, 1951].

10586. Seifert, Eva - Sobre: M. Criado de Val, Sintaxis del verbo español moderno, t. 1. - AlL, 5 (1952), 398-404. 10587 . Bull, William E. - "The intransitive reflexive: $i r$ and irse". $-M L J$, $3^{6}(1952), 382-386$.

10588. Irving, T. B. - "The Spanish reflexive and the verbal sentence". HispB, 35 (1952), 305-309.

10589. Alarcos Llorach, E. - "Perfecto simple y compuesto en español". RFE, 31 (1947); 108-139.

10590. Seifert, Eva - Sobre E. Alarcos Llorach, "Perfecto simple y compuesto en español". - AIL, 5 (1952), 395-398. 10591. Scazzocchio, LEA S. DE - "El futuro eventual en español. Una particularidad sintáctica del español a la luz de una forma griega. El futuro en los idiomas clásicos". - RFHC, 1951, núm. $7,167-177$.

10592. Deutschmann, Olaf - Sobre: Y. Malkiel, The Hispanic suffix "-(i)ego". - RJ, 4 (1951) [publ. 1952], 408-415. 10593. IAnNucci, James E. - Sobre: Y. Malkiel, The Hispanic suffix "-(i)ego". - HR, 21 (1953), 258-260.

10594. Holmes, Urban T., JR. - Sobre: Y. Malkiel, The Hispanic suffix "-(i) ego". - Sp, $27 \cdot(1952), 234-235$.

V. también núms. $10358-65,10454,10462$. $64,10524,10_{5}^{66-67}$

\section{Lexicografía y semántica}

10595. Enciclopedia universal ilustrada europeo-americana. Ts. 4, 5, 18 (2 parte) y 49 ; Apéndices 6 y 7 . - EspasaCalpe, Madrid, 1952, 1080, 1336, 1480 , 1460 y 1480 pp. - V. núm. 9377.

10596. TORO Y GisBert, M. DE - Nuevo pequeño Larousse ilustrado. - Larousse, París, 1952. 1520 pp.
10597. Gillet, Joseph E. - Sobre: M. Romera-Navarro, Registro de lexicografia hispánica. - HR, 21 (1953), 178190.

10598. OTs, J. M. - Sobre: R. Altamira y Crevea, Diccionario castellano de pa. labras juridicas y técnicas tomadas de la legislación indiana. - HAHR, 32 (1952), 393-395.

10599. Gill Gaya, Samule - Sobre: R. Altamira y Crevea, Diccionario casiellano de palabras juridicas y técnicas tomadas de la legislación indiana. - RHA, 1952, núm. 33, 105 -108.

1060o. Góncora, Mario - Sobre: R. Altamira. y Crevea, Diccionario castellano de palabras juridicas y técnicas tomadas de la legislación indiana. RChHG, 1952, núm. 119, 304-3o8.

10601. Villalba y Rubio, Firnando Diccionario geográfico universal. - Autor, Madrid, [1953]. $1757 \mathrm{pp}$.

106o2. Malaret, A. - "Lexicón de fauna y flora (cont.). - BICC, 8 (1952), 126157. - V. núm. 8585 .

10603. Malaret, Augusto - "Correcciones al Diccionario de americanismos y al Lexicón de fauna y flora". - UnivPB, 16 (1951), 374-421; 17 (1952), 27-61, 312-352.

10604. Machale, Carlos F. - De re lexicographica. La germania de los diccionarios académicos. - Madrid, 1953. 39 pp.

1060弓. Gili Gava, S. - "Cultismos en la germanía del siglo xri". - NRFH, 7 $(1953), 113-117$.

10606. Versión española del Vocabulario eléctrico internacional. Pról. de J. A. de Artigas e introd. de L. Lombardi.Madrid, s.f. xvi + $3_{01} \mathrm{pp}$.

10607 . Entrambasaguas, J. dE - Sobre: Versión española del Vocabulario eléctrico internacional. - RFE, $3^{6}$ (1952), 344-347.

10608. Bosflli, Carlo - Dizionatio italiano-spagnolo e spagnolo-italiano, - A. Garzanti, Milano, 1950. 2 ts.: xxxii + 479 y xvi +499 pp.

10609. Martínez Amador, Emilio M. Amador shorter Spanish dictionary. Spanish-English and English-Spanish. Heath \& Co., Boston [y: R. Sopena, Barcelona], 1953. xxxix $+555 \mathrm{pp}$. 10610. ArNold, Frederic K. - Sobre: E. M. Martinez Amador, Shorter Spanish dictionary. - HispB, $3^{6}$ (1953), $3^{87}$ 388 .

10611. García, Ángel Migura - Diccio- 
nario histórico enciclopédico de El Salvador. - El Salvador, 1950.

10612. Kahane, Henry y Renée, y ANDREAS TIETzE - "El término mediterráneo faluca". - NRFH, 7 (1953), 56-62. 10613. Corominas, J. - "Spanish deleznarse". - Word, 3 (1947), núms. 1-2. 10614. Salazar, Adolfo - "La guitarra, heredera de la kithara clásica". NRFH, 7 (1953), 118-126.

10615. Clavería, Carlos - "Terne". NRFH, 7 (1953), 127-133.

10616. Frenk Alatorre, Margir - "Designaciones de rasgos físicos personales en el habla de la ciudad de México". - NRFH, 7 (1953), 134-156.

10617. Vidal de Battini, Berta E. - "E1 léxico de los buscadores de oro de la Carolina, San Luis". - Homenaje a Fritz Krüger, 1 (Mendoza, 1952), 303333 .

10618. Vidal de Battini, Berta Elena "E1 léxico de los yerbateros". - NRFH, 7 (1953), 190-208.

V. también núms. 10366-81, 10454-61. $10525-27,10540,10557,10695,10651$, 10984 .

\section{Onomástica y toponimia}

lo6ig. Badfa Margarit, Antonio - "Aspects méthodologiques de la contribution de la botanique à la toponymie". - Troisième Congrès Intern. de top. et d'anthr. (Louvain, 1951), 3, 525-546.

10620. Bosch-Gimpera, P. - "Autour des problèmes de toponymie celtique en Espagne". - Troisième Congrès Intern. de top. et d'anthr. (Louvain, 1951), 3, $497-507$.

10621. López Santos, Luis - Influjo de la vida cristiana en los nombres de pueblos españoles. - Centro de Estudios de San Isidoro, León, 1952, $217 \mathrm{pp}$.

10622. Yndurárn, F. - Sobre: L. López Santos, Influjo de la vida cristiana en los nombres de pueblos españoles. AFAr, 5 (1953), 177-179.

10623. Rohtrs, G. - "Le suffixe préroman $-u e,-u y$ dans la toponimie aragonaise et catalane". - AFAr, 4 (1952), $129^{-1} 5^{2}$.

10624. Kuns, Alwin - "Zu den Flurnamen Hocharagons". - Homenaje a Fritz Krüger, 1 (Mendoza, 1952), 47-56.

10625. Roca Pons, J. - Sobre: M. García Blanco, Contribución a la toponimia aragonesa medieval. Los documentos reales pinatenses de Sancho Ramirez Pir, 7 (1951), 637.
10626. Cortés Vázquez, L. - "Un problema de toponimia española" [El nombre de Zamora]. - Zephyrus, 3 (1952). 10627. Dolç, Miguel - "Los primitivos nombres de Huesca". - Argensola (Huesca), 6 (1951), 153-165.

10628. Lida de Malkiel, Marfa Rosa "Para la toponimia argentina: Patagonia". - HR, 20 (1952), 321-323.

10629. RAYMOND, JoSEPH - "Water in Mexican place names". - Amer, 9 $\left(195^{2-53)}, 201-205\right.$.

1063o. Simún Dfaz, Jost - "Los apellidos en la poesía de los Siglos de Oro". RLit, I (1952), 47-55.

10631. Thompson, R. Wallace - "Ocho apodos en el Alto Aragón". - RDTP, 8 (1952), 465-47o.

V. también núms. 10382-93, 10454, 10513, $10532-34,1055^{2-53}, 10660$.

\section{Dialectología}

\section{Pen insular}

10632. Garcia-Lomas, G. - El lenguaje popular de las montañas de Santander. Fonética, recopilación de voces, refranes y modismos. - Publs. del Centro de Estudios Montañeses, Santander, 1949. lxxxix + 339 pp., ilustr.

10693. KRÜGER, F. - Sobre: G. GarcíaLomas, El lenguaje popular de las montañas de Santander. - AIL, 5 (1952), 388-989.

10634. Alonso, D. - "Del Occidente de la Península ibérica”. - NRFH, 7 (1953), 157-169.

10635. Krüger, Fritz - "En torno a dos palabras salmantinas: bica, antruejo". - NRFH, 7 (1953), 170-182.

10636. Garcfa, Constantino - Sobre: L. Rodríguez-Castellano, La variedad dialectal del Alto Aller. - RABM, $5^{8}$ (1952), 557-558.

10637 . Huarte, Fernando - Sobre: L. Rodríguez-Castellano, $L a$ variedad dialectal del Alto Aller. - AO, 3 (1953), 278-28o.

10638. Rohlfs, G. - Sobre: L. RodriguezCastellano, La variedad dialectal del Alto Aller. - ASNS, 190 (1953), p. 173 .

10699. Rohlfs, G. - "Los sufijos en los dialectos pirenaicos". - Pir, 7 (1951), $4^{6} 7 \cdot 525$.

10640. Roca Pons, J. - Sobre: V. García de Diego, "Notas sobre el pirenaico". - Pir, 7 (1951), 637-638.

10641. Roca Pons, J. - Sobre: A. Kuhn, 
"El aragonés, idioma pirenaico". - Pir, 7 (1951), 630-632.

10642. RocA Pons, J. - Sobre M. Alvar, "Más sobre pérdida de $f$ - inicial [en aragonés]", - Pir, 7 (1951), 632-633.

10643. Roca Pons, J. - Sobre: W. D. Elcock, "The evolution of $-l l$ - in the aragonese dialect". - Pir, 7 (1951), $634^{-6} 35$.

V. también núms. 10538, 10623-25.

Extrapeninsular

10644. Besso, Henry V. - "Bibliografía sobre el judeo-español". - Tribuna Israelita (México), 8 (1952), núm. 93, 28-32. [Son 134 fichas].

10645. Crews, Cynthia - Sobre: M. L. Wagner, "Espigueo judeo-español". VoxR, 12 (1951-52), $19^{2-198 .}$

10646. VAlle, RAfael H. - "El español de la América española". - $C u A, 11$ (1952), núm. 6, 217-224.

10647. Araujo, Orlando - Sobre: A. Rosenblat, La lengua y la cultura de His. panoamérica. Tendencias actuales. $R N C, 14$ (1952), núm. 95, 204-207.

10648. Navarro, Tomás - Sobre: M. L. Wagner, Lingua $e$ dialetti dell'America spagnola. - RRQ, 43 (1952), 69-7o.

10649. Flórez, Luis - Sobre: C. E. Kany, American-Spanish syntax. - BICC, 8 (1952), 215-217.

10650. Kiddle, Lawrence B. - Sobre: C. E. Kany, American-Spanish syntax. RomPh, 7 (1953-54), 366-372.

10651. Morínico, Marcos A. - "La formación léxica regional hispanoamericana". - NRFH, 7 (1953), 234-241.

10652. R[ODŔ́guez]-Castellano, L. - Sobre: T. Navarro Tomás, El español en Puerto Rico. - AO, 3 (1953), 272-278. 10653. Castellanos Y Bonilla, Isidoro De cómo se habla el español en Cuba. - La Habana, 1950. $5^{\circ} \mathrm{pp}$.

10654. Navarro, Tomás - "Observaciones sobre el papiamento". - NRFH, 7 (1953), 183-189.

10655. Tejera, Emiliano - Palabras indigenas de la isla de Santo Domingo. Caribe, Ciudad Trujillo, 1951, xii + $5^{16}$ pp. - V. núm. 9443 .

10656. KiddLe, Lawrence B. - “Turkey in New Mexican Spanish". - RomPh, 5 (1951-1952), 190-197.

10657. Wagner, M. L.-Sobre: V. M. Suárez, El Español que se habla en Yucatán. - VoxR, 12 (1951-52), $189-192$. 10658. Mediz Bolio, Antonio - "Interinfluencia del maya con el español de
Yucatán". - YMTh, 12 (1951), 153-154, $15^{6 \cdot 161}, 167-168,17^{1-1} 74$. - V. núm. 8660 .

10659. Robe, Stanley L. - "Algunos aspectos históricos del habla panameña”. - NRFH, 7 (1953), 209-220.

1066o. Jover Peralta, ANSElmo-El guarani en la geografia de América. Tupá, Buenos Aires, 1950. xlvi +272 pp.

10661. Ronchi March, C. A. - Sobre: A. Jover Peralta, El guarani en la geografia de América. - AIL, 5 (1952), $426 \cdot 43$.

10662. Plath, Oreste - Alimentación y lenguaje popular. - Santiago de Chile, 1949. 18 pp. [Sep. de la Revista MédicoAsistencial].

10663. Oroz, Rodolfo - "La carreta chilena sureña". - Homenaje a Fritz Krüger, 1 (Mendoza, 1952), 365-398.

V. también núms. 10573-74, 10602-03, 10616-18.

\section{LITERATURA}

\section{ESTUDIOS GENERALES}

\section{Teoria literaria}

10664. WEHRLI, MAX - Allgemeine Literaturwissenschaft. - Francke, Bern, 1951. 168 pp. (Wissenschaftliche Forschungsberichte, 3).

10665. Mulot, Arno - Zur Neubesinnung der Literaturwissenschaft". - GRM, 1 (1951), núm. 3.

10666. Benedetti, M. - Sobre: G. de Torre, Problemática de la literatura. Num, 4 (1952), 184-185.

10667. Gano, J. L. - Sobre: G. de Torre, Problemática de la literatura. - RevEP $195^{2}$, núm. 64, 182-184.

10668. Fernández SuÁrez, A. - Sobre: G. de Torre, Problemática de la literatura. - Sur, 1952, núms. 207/8, 118 ss.

10669. LoAyzA, LuIs - Sobre: G. de Torre, Problemática de la literatura. - MdS, 9 (1953), núm. 25, 91-92.

10670. Cressot, Marcel - Le style et ses techniques. - Presses Universitaires, Paris, $195^{1,} 253 \mathrm{pp}$.

10671. Vilariño, IDEA - Sobre: M. Cressot, Le style et ses techniques. - Núm, 4 (1952), 195-196.

10672. KERKHOFF, EMMY - De Kunst der Stijlinterpretatie. Een pleidooi voor functionele stilistiek. - Meulenhoff, Amsterdam, 1951, $21 \mathrm{pp}$. 
10673. Bucca, S. - Sobre: G. Devoto, Studi di stilistica.-AIL, 5 (1952), 354$35^{6 .}$.

10674. Hatzfeld, Helmut - "The situation in the field of Hispanic style studies". - Homenaje a A. M. Huntington (Wellesley, Mass., 1952), 233-252.

10675. Granero, I. E. - El arte de la retórica. - Univ. de Cuyo, Mendoza, 1951; t. 1: 206 pp.

10676. Arbusow, LeONid - Colores rhetorici. - Vandenhoeck und Ruprecht, Göttingen, 1948, 124 Pp.

10677. LidA DE Malkiel, M. R. - Sobre: L. Arbusow, Colores rhetorici. RomPh, 7 (1953-54), 223-225.

19678 . Croce, B. - Primi saggi: La storia ridotta sotto il concetto generale dell' arte; La critica letteraria. $3^{\text {a }}$ ed. - Laterza, Bari, 1951. xvi + 206 pp.

10679. Paulhan, Jean - Petite préface à toute critique. - Minuit, Paris, 1951. $110 \mathrm{pp}$.

10680. TATe, AllfN - "Is literary criticism possible?" - Partisan Review, 19 (1952), 546-557.

10681. Levin, Harry (ed.) - Perspectives of cristicism. - Harvard Univ. Press, Cambridge, $195^{\circ}$. xiv $+248 \mathrm{pp}$.

10682. Wimsat, W. K., JR. - Sobre: Perspectives of criticism, ed. H. Levin. CompL, 3 (1951), 368-372.

10683. Stallman, Robert W. - The critic's notebook. - Univ. of Minnesota Press, Minneapolis, 1950. $\mathrm{xv}+303 \mathrm{pp}$. 10684. Stallman, R. W. (ed.) - Critiques and essays in criticism, 1920-1948. - Ronald, New York, 1949. xxii + 571 pp.

10685. Schorer, M.; J. Miles; G. MCKeNzIE (eds.) - Criticism. The foundations of modern literary judgment. - Harcourt, New York, 1948. xi + 553 pp.

10586. Trowbridge, Hoyt - Sobre: The critic's notebook, ed. R. W. Stallman; Critiques and essays in criticism, ed. R. W. Stallman; Criticism, ed. M. Schorer, J. Miles, G. McKenzie. - CompL, 3 (1951), $35^{6-364}$.

10687 . KNAUER, K.- "Quelques aspects de l'exigence d'exactitude en critique littéraire". - EPM, 1951, núm. 129, 201-208. 10688. Croce, Benidetto - Letture di poeti e riflessioni sulla teoria e la critica della poesia. - Laterza, Bari, $195^{\circ}$. $33^{8} \mathrm{pp}$.

10689. Montagna, G. - Sobre: B. Croce, Letture di poeti e riflessioni sulla teoria e la critica della poesia.-LR, 8 (1954). 61-62. 106go. Cairns, Huntington (ed.). - The limits of art. Poetry and prose chosen by ancient and modern critics. - Routledge and Kegan Paul, London, 1951. xliv + $1473 \mathrm{pp}$.

10691. Croce, B. - Filosofia, poesia, storia. - R. Ricciardi, Milano-Napoli, $195^{1 .}$

10692. Santoli, V. - Sobre: B. Croce, Filosofia, poesia, storia. - RLM, 1952, núm. 2.

10693. Staiger, E. - Grundbegriffe der Poetik. 2. Aufl. - Atlantis. Zürich, 1951. 264 pp.

10694. Martínez Bello, Antonio - Sobre: G. Diaz-Plaja, Poesía y realidad. $R B N, 3$ (1952), 325-333.

10695. DédéYan, C. - "La notion de poésie dans le cosmopolitisme préromantique (1790-1815)". - Revue des Sciences Humaines (Lille), 1951.

10696. Eliot, T. S. - Poetry and drama. - Faber \& Faber, London, 1951, 35 pp. [Y también: Harvard Univ. Press, Cambridge, 1951. 44 pp.].

10697. Wespi, Hans-Ulrich - Die Geste als Ausdrucksform und ihre Beziehungen zur Rede. - Francke, Bern, 1949. (Romanica Helvetica, 33).

10698. Embler, Weller B. - "The novel as metaphor". - Etc., 10 (1952), 3-11. 10699. MendiLow, A. A. - Time and the novel. Introd. by J. Isaacs. - Nevill, London, 1952, $255 \mathrm{pp}$.

10700. JUnker, Albert - "Formen und Wandlungen des historischen Romans". - GRM, I (1950-51), núm. 1.

10701. Neri, F. - Letteratura e leggende. - Torino, $195 \mathrm{I}$.

10702. Dédéyan, Charles - Sobre: H. Peyre, Les générations littéraires. RLComp, 26 (1952), 403-409.

10703. Hardré, JacQues-Sobre: H. Peyre, Les générations littéraires. - CompL, 3 $\left(195^{1}\right), 181-183$.

10704. WeIdLÉ, Wladimir - Ensayo sobre el destino actual de las letras y las artes. Trad. C. M. Reyles. 2 à ed. - Emecé, Buenos Aires, 1951. 225 pp.

V. también núms. $10345,10348$.

\section{RELACIONES LITERARIAS}

Influencias extranjeras

10705. Martín Gabriel, A. - "Heliodoro y la novela española (apuntes para una tesis)". - CLit, 8 (1950), 215-234.

10706. López Estrada, Francisco - "Suerte $y$ olvido de la Historia etiópica de 
Heliodoro". - Clav, 3 (1952), núm. 13, $1 \%-19$.

10707. Menéndez Pelayo, Marcelino Bibliografia hispano-latina clásica. Ts. $4^{-6}$ (Horacio) y 7 (Hostio-Plauto). C. S. I. C., Santander, 1951. ix +535 , 335,585 y 423 pp. (Obras completas). V. núm. 7172.

10ךo8. Palacín, G. B. - "Influencia de Castiglione en las letras cspañolas". Le Lingue del Mondo, 17 (1952), 195197 . [Sobre todo en Juan de Valdés].

10709. Hamilton, Rita - "Villalón et Castiglione". - $\mathrm{BHi}, 54$ (1952), 200202.

10710. López Estrada, F. - Sobre: G. C. Rossi, A poesia épica italiana no século xvi na literatura portuguesa. - CompL, 4 (1952), 279-280.

10711. Selig, K. L. - "The Spanish translation of Cesare Ripa's Iconologia”. Ital, 28 (195̆1), núm. 4 .

10712. TORTORETo, A. - "Il Tasso in Ispagna ed in Portogallo". - Studi Tassiani, 1 (1950).

10713. Blecua, J. M. - Sobre: C. Clavería, "Le chevalier délibérè" de Olivier de la Marche y sus versiones españolas del siglo xvi. - Ins, 7 (1952), núm. 83 .

10714. Cardenal Iracheta, M. - Sobre: C. Claveria, "Le chevalier délibéré" de Olivier de la Marche y sus versiones españolas del siglo xvi. - Clav, 3 (1952), núm. 13, 67-68.

10715. Pierce, Frank - Sobre: C. Clavería, "Le chevalier délibéré" de Olivier de la Marche y sus versiones españolas del siglo xvi. - MLR, 47 (1952), 252. 253.

10716. Marichal, JUaN - "Montaigne en España”. - NRFH, 7 (1953), 259-278. 10717. Escarpit, Robert - Sobre: E. Pujals, Espronceda y Lord Byron: RLComp, 27 (1953), 231-232.

10718. Northup, G, T. - Sobre: E. Pujals, Espronceda y Lord Byron. - HR, 21 (1953), $75-76$.

10719. R[Umeau], A. - Sobre: E. Pujals, Espronceda y Lord Byron. - BHi, 54 (1952), 232-233.

10720. EnglekiRK, John E. - A literatura norteamericana no Brasil. - México, 1950. $185 \mathrm{pp}$.

10721. Moser, Gerald M. - Sobre: J. E. Englekirk, A literatura norteamericana no Brasil. - HR, 21 (1953), 361-363.

$V$. también núms. 10182.89, 10204, 10268, 10293-94, $10966-67, \quad \log 89-90,11003$.
Influencias hispánicas

10722. RugGierI, RUGgero M. - "Li fatti de Spagna", testo settentrionale trecentesco già detto "Viaggio di Carlo Magno in Ispagna". T. 1. - Soc. Tip. Modenese, Modena, 1951. $182 \mathrm{pp}$. (Istituto di Filol. Romanza della Uniu. di Roma, Studi $e$ Testi).

10729. Frank, István-Sobre: R. M. Rug. gieri, "Li fatti de Spagna", testo settentrionale trecentesco già detto "Viaggio di Carlo Magno in Ispagna". - Ro, 74 (1953), 244-250.

10724. Carballo Picazo, A. - Sobre: De sainte Léocade au tans que sainz $\mathrm{Hyl}$ defons estoit arcevesques..., miracle versifié par G. de Coinci, ed. E. Vilamo-Pentti. - RFE, $3^{6}$ (1952), 147-149. 10725 . Janelle, Sister Marie Thomas The role of Spain in the works of Alain-René Lesage. - [Tesis de la Univ. de Fordham, 1951].

10726. Filippini, Felice - Figaro ... Sag. gio sul celebre personaggio di Beaumarchais. - Cenobio, Lugano, $195^{2}$. $5^{8} \mathrm{pp}$.

10727. Day, Robert A.-"Madame d'Aulnoy on the Lettres portugaises"-MLN, $67\left(195^{2}\right), 544^{-5} 4^{6}$.

10728. Aveline, Claude - ...Et tout le reste n'est rien (La réligieuse portugaise avec le texte de ses lettres). - Mercure de France, Paris, 1951. $3^{01} \mathrm{pp}$.

10729. Le Gentil, Georges - "La question de la réligieuse portugaise". RLComp, 26 (1952), 423-431.

10730 . SPITZER, Leo - "Les Lettres portugaises”. - RF, 65 (1953), 94-135.

10731. Halperin Donghi, Tulio - "Las cartas de una peruana" [por Madame d'Happoncourt de Graffigny, 1747]. Sur, 1953, núms. 221/2, 94-102.

10732. Staiger, A. - "Voltaire und Spanien". - Festgabe Spoerri, Zürich, $195^{\circ}$. 10733. Morand, Paul - Le flagellant de Séville. $6^{\mathrm{e}}$ ed. - Fayard, Paris, $195^{1}$. $406 \mathrm{pp}$.

10734. Grillparzer, F. - The Jewish of Toledo. Trans, by A. Burkhard. - The Register Press, Yarmouth Port (Mass.), 1953. 157 pp.

10735. SCHimmerl, E. - "Die spanischen Einflüsse in Grillparzers Lustpiel Weh dem, der lügt". - MLQ, 12 (1951), 6771 .

10736. SFidlin, O. - "Picaresque elements in Thomas Mann's works". - MLQ, 12 (1951) , 183-200.

10737. BeChFr, Ularich - Brazilianischer 
Romanzero. - Frick, Wien, 1950. 112 pp.

10738. Maceina, A. - Der Grossinquisitor. Geschichtsphilosophische Deutung der Legende Dostojewskys. - Heidelberg, 1952. $34^{\circ} \mathrm{pp}$.

10739. Williamson, George-The Senecan amble: a study in prose form from $\mathrm{Ba}$ con to Collier. - Faber and Faber, London [y también: University of Chicago Press, Chicago], 1951. 377 pp. 10740. X. - Sobre: G. Williamson, The Senecan amble. - TLS, 2 nov. 1952, p. 694 .

10741. Bush, Douglas - Sobre: George Williamson, The Senecan amble. $M L N, 68$ (1953), 247-25o.

10742. KimmelmaN, Elaine - "A forerunner of Euphuism". - Boston Public Libr. Quart., 2 (1950). [Fray Antonio de Guevara].

10743. Irving, Washington - Cuentos de la Alhambra. - Dolar, Madrid, [1952]. 160 pp. (Escritores célebres, 32.).

10744. Irving, Washington - The Alhambra. - Macmillan, New York, 1953. vii + 280 pp.

10745. Espinoza, EnRIQUe - Tres clásicos ingleses de la pampa: F. B. Head, William H. Hudson y R. B. Cunninghame Graham. - Babel, Santiago de Chile, $195^{1 .} 7^{8}$ pp.

10746. Martínez Estrada, Ezequiel $-E l$ mundo maravilloso de Guillermo Enrique Hudson. - Fondo de Cultura Económica, México-Buenos Aires, 1951. 343 pp.

10747. GREenE, T.-"D. H. Lawrence and the Quixotic hero". - Sewanee Rev., 59 (1951).

V. también núms. $10942,10945-46$.

\section{Literatura comparada}

10748. Höllerer, Walter - "Methoden und Probleme vergleichender Literaturwissenschaft". - GRM, 2 (1951-52), núm. 2.

10749. W[ELLEK], R. - Sobre: F. Baldensperger y W. P. Friederich, Bibliography of comparative literature. CompL, 4 (1951-52), 90-92.

1075o. Munteano, B. - Sobre: F. Baldensperger y W. P. Friederich, Bibliography of comparative literature. RLComp, 26 (1952), 273-286.

10751. Bibliographie générale de la littérature comparée. Années 1949-1950. Boivin, Paris, s. f. $46 \mathrm{pp}$.

10752. Krauss, Werner - "Der Stand der romanistischen Literaturgeschichte an der Leipziger Universität". - Wiss. Zeitsch. der Univ. Leipzig, 1951-52, núm. 3, 1-12.

10753. W[ELLEK], R. - Sobre: Forschungsprobleme der vergleichenden Literaturgeschichte, ed. K. Wais. - CompL, 4 (1952), 277-279.

10754. HarvitT, H. - Sobre: M. F. Guyard, La littérature comparée.-French Rev. (New York), 1953 .

10755. Malone, D. H. - Sobre: M.-F. Guyard, La littérature comparéê.-YCL, 2 (1953), 6o-62.

10756. Shackleton, R. - Sobre: M.-F. Guyard, La littérature comparée. - FS, 6 (1952), $3^{80-381 .}$

10757. Voisine, J. - Sobre: M.-F. Guyard, La littérature comparée. - RLComp, $26\left(195^{2}\right), 287 \cdot 288$.

10758. Momigliano, Atrilio (ed.) - Letterature comparate. - Marzorati, Milano, 1948. $3^{82}$ pp. [Contiene, entre otros, un estudio de Alda Croce sobre "Relazioni della letteratura italiana con la letteratura spagnuola"].

10759. F[RIEDERICH], W. P. - Sobre: A. Momigliano (ed.), Letterature comparate. - CompL, 3 (1951), 83-85.

1076o. Eppelsheimer, HaNs W. - Handbuch der Weltiteratur. - Klostermann, Frankfurt a. M., $1947^{-1950 .} 2$ ts.: $390 \mathrm{y}$ 414 pp.

10761. W[ELLEK], R. - Sobre: H. W. Eppelsheimer, Handbuch der Weltiteratur. - CompL, 3 (1951), 185-186.

10762. Shipley, Joseph T. (ed.) - Dictionary of world literature. Criticism, forms, technique. New Revised edition. - Philosophical Library, New York, 1953. xii $+453 \mathrm{pp}$.

10763. Holmes, U. T. - Sobre: J. T. Shipley (ed.), Dictionary of world literature - YCL, 2 (1953), 62-63.

${ }_{10764}$. Dizionario letterario Bompiani delle opere e dei personaggi di tutti $i$ tempi $e$ di tutte le letterature. Ts. 8 y 9. - V. Bompiani, Milano, 1950. 880 y $37^{\circ}$ pp. - V. núm. 6131 .

${ }_{107} 6_{5}$. W[ELLEK], R. - Sobre: Dizionario letterario Bompiani.-CompL, 3 (1951), 364-366.

10766. Frauwallner, Erich y otros (eds.) - Die Weltiteratur. - Hollinek, Wien, 1951-1952. $1124 \mathrm{pp}$.

10767. BEAv, A. E. - Sobre: Walter Muschg, Tragische Literaturgeschichte. $-B d F, 13$ (1952), 164-168.

10768. Wölcken - Sobre: G. Highet, The classical tradition. - ASNS, 190 (1953), p. 133 . 
10769. Schottenloher, KarL - Bücher bewegten die Welt: eine Kulturgeschichte des Buches. - Hiersemann, Stuttgart, 1951-52. 612 pp.

10770. Thompson, LAwrence S. - Sobre: K. Schottenloher, Bücher bewegten die Welt: eine Kulturgeschichte des Buches. - $S p, 28$ (1953), 186-18g.

10771. VázQuez de Parga, L. - Sobre: E. R. Curtius, Europäische Literatur und lateinisches Mittelalter.-Clav, 1 (1950), núm. 6, 76-77.

10772. Van Jan, E. - Sobre: E. R. Curtius, Europäische Literatur und lateinisches Mittelalter. - Deutsche Literatur. zeitung, 72 (1951), 202-207.

10773. Politzer, R. L. - Sobre: E. R. Curtius, Europäische Literatur und lateinisches Mittelalter. - CompL, 5 (1953), 171-176.

10774. Neubert, F. - Sobre: E. R. Curtius, Europäische Literatur und lateinisches Mittelalter. - Neuphilologische Zeitschrift, 3 (1951), 169-174.

10775. Battistessa, Angel J. - Sobre: E. R. Curtius, Europäische Literatur und lateinisches Mittelalter.-Log, 6 (1951), 262-274.

10776. Auerbach, Erich - Sobre: Karl Vossler, Die Dichtungsformen der Romanen. - MLN, 67 (1952), 129-131.

10777. Beau, Albin Eduard - Sobre: K. Vossler, Die Dichtungsformen der Romanen. - Biblos, 28 (1952), 515-517.

10778. Glasser, RICHARD - Sobre: Karl Vossler, Die Dichtungsformen der Romanen. - RF, 63 (1951), 433-437.

10779. WAIs, KURT - Sobre: K. Vossler, Die Dichtungsformen der Romanen. ASNS, 189 (1953), 244-246.

10780. Chantraine, P. - Sobre: R. B. Onians, The origins of European thought about the body, the mind, the soul, the world, time and fate.-RevPh, 27 (1953), 203-204.

10781. EMMEL, H. - Formprobleme des Artusromans und der Graldichtung. Francke, Bern, 1951 y 1952. 184 pp.

10782. Loomis, R. S. - Sobre: H. Emmel, Formprobleme des Artusromans und der Graldichtung. - $S p, 28$ (1953),158. 159 .

10783. RUPP, HEInz - Sobre: H. Emmel, Formprobleme les Artusromans und der Graldichtung. - ASNS, 190 (1953), p. 79 .

10784. Charlier, G. - Sobre: M. I. Gerhardt, La Pastorale. Essai d'analyse littéraire. - RBPH, 30 (1952), 886-887. 10785. KrölL, HeINz - Sobre: M. I. Ger- hardt, La pastorale. Essai d'analyse littéraire. - BdF, 13 (1952), 179-182.

10786 . WAIs, KURT - Sobre: M. I. Gerhardt, La pastorale. Essai d'analyse lit téraire, - ASNS, 190 (1953), 162-163.

10787 . LECOY, FúlIX - Sobre: Rita Lejeune, Recherches sur le thème: les chansons de geste et l'histoire. - Ro, $73(1952), 412-419$.

10788. Knudson, Charles A. - Sobre: I. Siciliano, Les origines des chansons de geste. - RomPh, 7 (1953-54), 95-99.

10789. Köhler, ERICH - Sobre: I. Siciliano, Les origines des chansons de geste. - RJ, 4 (1951) [publ. 1952], 448-452. 1079o. Menéndez Pidal, R. - La épica española y la francesa comparadas. Univ. de Segovia, Segovia, 1951. $18 \mathrm{pp}$. 10791. Geschiere, L. - "A propos d'une publication récente sur la Chanson de Roland". - N, 37 (1953), 170-173. [Sobre: J. Horrent, La "Chanson de Ro. land" dans les littératures française et espagnole au moyen âge].

10792. Goosse, ANDRÉ - Sobre: J. Horrent, La "Chanson de Roland" dans les littératures française et espagnole au moyen âge. - LR, 7 (1953), 60-62.

10793. Peckham, P. G.-Sobre J. Horrent, La "Chanson de Roland" dans les littératures française et espagnole au moyen age. - RRQ, 43 (1952), 57-59.

10794. Rohlfs, G. - Sobre: J. Horrent, La "Chanson de Roland" dans les littératures française et espagnole au moyen age. - ASNS, 189 (1952), p. 71.

10795. Walpole, R. N. Sobre J. Horrent, La "Chanson de Roland" dans les littératures française et espagnole au moyen âge.-RomPh, 6 (1952-53), 337-348. 10796. Willis, RAYMOND S., Jr.-Sobre: J. Horrent, La "Chanson de Roland" dans les littératures française et espagnole au moyen âge. $-H R, 21$ (1953), 53-59.

10797. Walpole, RoNald N.--"Two comments on recent studies on the Chanson de Roland".-RomPh, 6 (1952-53), $34-44$.

10798. CoHen, R. - The "Roland" and the "Cid". A comparative structural analysis. - [Tesis de la Universidad de Columbia, 1950].

10799. Monte, Alberto DeL - "Introduzione all' ermetismo medievale (stile oscuro latino e trobar clus) ". $-P P N, 3$ (1948), núm. 7 .

10800. KöHLER, ERICH - "Zum trobar clus der Trobadors". $-R F, 64$ (1952), 71 101.

10801. Ross, Werner - "Uber den soge- 
nannten Natureingang der Trobadors". $-R F, 65$ (1953), 49-68.

10802. Jones, Charles W. (ed).-Medieval literature in translation-Longmans, Green and Co., Toronto, 1950, $\mathrm{xx}+$ 1004 pp.

10803. SCHNEIDER, H.-"Weltliteratur und Nationalliteratur im Mittelalter". Euphorion, $45\left(195^{\circ}\right)$.

10804. SyPherd, Wilbur OWen - Jephtah and his daughter. A study in comparative literature. - The Univ. of Delaware, Newark, 1948. xiv + 277 pp.

10805. LidA DE MALKIEL, M. R. - Sobre: W. O. Sypherd, Jephtah and his daughter. - RomPh, 7 (1953-54), 258-259.

10806. Payne, Robert O. - Sobre: H. R. Patch, The other woild, according to descriptions in medieval literature. Harvard Univ. Press, Cambridge, $195^{\circ}$. ix $+3^{86} \mathrm{pp}$.

10807. H[ATZFELD], H. - Sobre: W. P. Friederich, Dante's fame abroad, $135^{\circ-}$ 185o. - CompL, 3 (1951), 372-374.

10808. Batard, Y. - Sobre: W. P. Friederich, Dante's fame abroad. - RLComp, 27 (1953), 214-221.

10809. RüEgG, August - Sobre: W. P. Friederich, Dante's fame abroad, 13501850. - ZRPh, 67 (1952), 381-384.

10810. RÜEGG, W. - "Ein Führer zum Nachleben antiker Autoren in Mittelalter und Renaissance". - Museum Helveticum, $195^{\circ}$.

10811. Talbert, Ernest W. - "Recent literature of the Renaissance". - $S P h$,

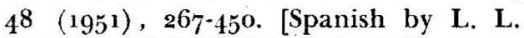
Barrett and S. E. Leavitt]. - V. núms. 6332 y 6733 .

10812. Nelson, Lowry, JR. - Sobre A. Coutinho, Aspectos da literatura barroca. - Compl, 5 (1953), 169-171.

10813. Derby, J. Raymond (ed.) - “The romantic movement: a selective and critical bibliography for the year 1951 ". -PhQ, 31 (1952), 97-155. [Spanish by E. H. Hespelt and N. B. Adams; Portuguese by $\mathrm{G}$. Moser]. - V. núm. 6724. 10814. DockhorN, K.- "Die Rhetorik als Quelle des vorromantischen Irrationalismus in der Literatur- und Geistesgeschichte".-Nachrichten der Akad. der Wissenschaften in Göttingen, 1949, 109$15^{\circ}$.

10815. Friedrich, Hugo - Sobre: K. Dock horn, "Die Rhetorik als Quelle des vorromantischen Irrationalismus in der Literatur- und Geistesgeschichte". $R F, 65$ (1953), $174^{-17} 6$.

10816. Dell'Isola, M. - Carducci nella letteratura europea. - Malfasi, Milano, 1951. - V. RFH, núm. 259.

10817. Pabst, Walter - Sobre: E. R: Curtius, Kritische Essays zur europäischen Literatur. - RJ, 4 (1951) [publ. 1952], $445-44^{8}$.

10818. Rohlfs, G.-Sobre:- E. R. Curtius, Kritische Essays zur europäischen Literatur. - ASNS, 189 (1952), 69-7o.

10819. RychNER, MAX - Zuz europäischen Literatur zwischen zwei Weltkriegen. 2. Aufl,-Manesse, Zürich, $195^{1} \cdot 39^{2} \mathrm{pp}$. 10820. WANDRUSZKA, M. - Angst und Mut [in der abendländischen Dichtung]. Stuttgart, $195^{\circ}$.

10821. Li Carrillo, Víctor - Sobre: Ernest Kreuder, Zur literarischen Situation der Gegenwart. - MdS, 8 (1952), núm. 22, 89-9o.

V. también núms. 10192, 10449 .

\section{LITERATURA HISPANO-LATINA}

10822. [SÉnECA] - De la clémence. Texte revu, accompagné d'une introduction, d'un commentaire et d'un Index omnium uerborum, par Paul Faider, Ch. Favez et Paul van de Woestijne. II: Commentaire et Index omnium uerborum.-De Tempel, Brugge, 1950. $225 \mathrm{pp}$. 10823. Grimal, P. - Sobre: Séneca, De la clémence, ed. P. Faider, Ch. Favez $\mathrm{ct}$ P. van de Woestijne.-REA, 54 (1952), 179-184.

10824. Giancotti, F. - "Note alle Tragedie di Seneca”. - RFIC, $3^{\circ}$ (1952), núm. 2.

10825. Stackmann, Karl - "Seneca's Agamemnon. Untersuchung zur Geschichte des Agamemnon-Stoffes nach Aischylos". -CM, 11 (1950), núms. 1-2.

10826. [Ś́NECA] - "Hercules furens" en Euripides' “Heracles". Ed. Th. B. B. Siemers. - Heerlen, 1951. 112 pp.

10827. [M ARCIAL] - Epigrammaton libri $X I Y$. Iterum recensuit C. Giarratano.Paravia, Torino, $195^{1}$. xxxvi $+370 \mathrm{pp}$. 10828. Luigr, P. - Marziale. - Giornale Italiano di Filologia, Napoli, $195^{\circ}$. $224 \mathrm{pp}$.

10829. Hudson-Williams, A.- "Some other explanations of Martial". - The Classical Quarterly, 2 (1952).

1083o. Torres, Casimiro - "El primer bibliotecario español, Cayo Julio Higynio". - BUSC, $195^{\circ}$, núms. $55^{-56}$.

10831. Madoz, J.-Segundo decenio de estudios sobre Patristica española (I97I1950). - Fax, Madrid, 1951. (Estudios Onienses, I, 5).

10832. Lfón Tello, F. J. - "La teoría 
de la música en las Etimologias de San

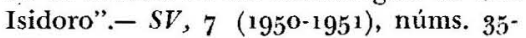
38.

10833. SÁnchez Alonso, B.-Sobre: Chronica Adephonsi Imperatoris, ed. L. Sánchez Belda. - RFE, $3^{6}$ (1952), 338-339. 10834. H[Igounet], CH. -Sobre: Chronica Adephonsi imperatoris, ed. L. Sánchez Belda. - $B H i, 54$ (1952), p. 226.

10835. LidA de MALKIEL, M. R. - "La Garcineida de García de Toledo." NRFH, 7 (1953), 246-258.

10836. Green, Otis H.-Sobre: Ángel Losada, Juan Ginés de Sepúlueda a través de su "Epistolario" y nuevos documentos. - HR, 20 (1952), 77-78.

V. también núms. 10717-19.

\section{LITERATURA HISPANO-ORIENTAL}

10837. IRving, T. B.-"Spanish mysticism: Islamic and christian". - Islamic Literature, 3 (1951).

10898. Granja, Fernando de la-"Los estudios sobre poesía arábigo-andaluza". $-A l A n, 18$ (1953), 224-229.

10839. García Gómez, Emilio-Poesía arábigoandaluza. Breve sintesis histórica.Inst. Egipcio de Estudios Islámicos, Madrid, 1952. 92 pp.

10840. NYKL, A. R. - "Hispano-Arabic poets in The Ioor nights." - Homenaje a A. M. Huntington (Wellesley, Mass., 1952), 477-49o.

10841. Quirós Rodríguez, Carlos-Poetas hispanoárabes. Interpretados en verso castellano.-Madrid, 1952.84 pp., ilustr. 10842. Morfland, H. - Arabic-Andalousian casidas. - London, 1949.

10843. Arberry, A. J. (transl.)-Moorish Poetry. A translation of The Pennants, an anthology compiled in 1243 by the Andalusian Ibn Said. - Cambridge Univ. Press, London, 1953. $x x+219 \mathrm{pp}$. 10844. Grunebaum, G. E. von - Sobre A. J. Arberry, Moorish poetry. - $s p$, 28 (1953), 856-857.

10845. Mele, Eugenio-"Nota a una poesiuola tradotta dallo spagnuolo". $-L M$, 3 (1952), 68-75. [El poema árabe a la palmera, traducido al castellano por $\mathrm{J}$. A. Conde, Valera, etc., y al italiano por Jacobo Sanvitale].

\section{LITERATURA CATALANA}

10846. Dolç, Miguel (ed).- Llibre de Sant Jordi. - Selecta, Barcelona, 1952. 249 pp. (Bibl. Selecta, 104).

10847. Lewent, Kurt - "Pour le texte de quatre pastourelles de Cerveri, dit de
Girona". - Ro, 74 (1953), 228-239, 390419. [Rectificaciones a M. de Riquer, Obras completas de... Cerveri de Girona].

10848. RiQuer, M. DE - "Para la cronología del trovador Cerveri". - EMP, 3 $3^{61-412 .}$

10849. RiQuer, M. DE - "Un nuevo manuscrito con versiones catalanas de Arnau de Vilanova". - Analecta Sacra Tarraconensia, 22 (1949), 1-20.

10850. TATE, RoberT B. - "Joan Margarit i Pau, Bishop of Gerona." - $S p, 27$ (1952), 28-42.

10851. Carrì̀?es, Marcel - "Le roman occitan et catalan du $\mathrm{XvI}^{\mathrm{e}}$ au $\mathrm{xx}^{\mathrm{e}}$ siècle". - RLR, 1950, 237-268; 1951, 4368.

10852. Sanchis Guarner, Manuet, - Els poetes romántics de Mallorca. - Moll, Palma de Mallorca, 1950. 28 pp.

10853. Pintó, A. - "Poesía catalana contemporánea (1939-1951)". - RLit, 1 $\left(195^{2}\right), 475-480$.

10854. Maragall, Joan - Poesies. Selecció. - Barcelona, 1953. 42 pp.

10855. Carner, Josep - Arbres. Poesies. Nota preliminar de M. Manent. - Selecta, Barcelona, [1953]. 239 pp.

10856. Romev, Josep - Obra poética. Selecta, Barcelona, s. a. 242 pp.

10857. Cabañas, Pablo - Sobre: Josep Romeu, Obra poética.-Arb, 22 (1952), $455-457$.

10858. Sanchis Guarner, M. - Els poetes insulars de postguerra. - Moll, Palma de Mallorca, 1951. 144 pp.

10859. Alcover, Antoni MA. - Rondaies mallorquines d'en Jordi d'es Recó. $5^{\text {á }}$ ed. - Moll, Palma de Mallorca, 19371952. 14 ts., 80 pp. c/u.

\section{LITERATURA GALLEGA, PORTUGUESA Y BRASILE.̃AA}

1086o. Cidade, H. - Lições de cultura e literatura portuguesas. I: Séculos xv, xvi $e$ xvii. $3^{\mathrm{a}}$ ed. - Coimbra, 1951. 455 pp. - V. RFH, núm. 3572.

10861. Le Gentil, P. - Sobre: F. de Figueiredo, Estudos de literatura. $-\mathrm{BH}$, 54. (1952), 89-9o.

10862. Soares Amora, A. - "Fidelino de Figueiredo". - YCL, 2 (1953), 49-51.

10863. Fernández Pousa, R. - Selección literaria del idioma gallego (siglos $x i$. $x x)$. Pról. de S. Montero Díaz. - Madrid, 1951. $196 \mathrm{pp}$.

10864. Álvarez Blázquez, Xosé MA. (ed.) -Escolha de poesia galega. I: Escola medieval galego-portuguesa (1198-1346). 
Notas de... - Edit. Galaxia, [Vigo], 1953. 220 pp.

10865. Massaud, MoIsés - $O$ processo dialéctico-narrativo na "Demanda do Santo Graal". - São Paulo, 1951. 69 Pp.

10866. Ferreira da Cunha, Celso - $O$ Cancioneiro de Joan Zorro. Aspectos lingüísticos, texto crítico, glossário. Rio de Janeiro, 1949. xxiii +97 pp.

10867. Ferreira da Cunha, Celso $-A$ margem da poética trovadoresca. $O$ regime dos encontros vocálicos interverbais. - Rio de Janeiro, 1950. 93 Pp.

10868. Rodrigues Lapa, M. - Sobre: C. Ferreira da Cunha, $A$ margem da poética trovadoresca. - NRFH, 8 (1954), $81-86$.

10869. Lindley Cintra, L. F. (ed.) - Crónica geral de Espanha de 1344. T. 1. Acad. Portuguesa da História, Lisboa, 1951. $600 \mathrm{pp}$.

1087o. Rłvah, I. S. - Sobre: Crónica geral de Espanha de 1344, ed. L. F. Lindley Cintra. - BEPI, 16 (1952), 241-244.

10871. Costa Pimpão - "Terão aparecido as crónicas perdidas de Fernão Lopes?" - Biblos, 27 (1951), 27-41.

10872. Piper, Anson C. - The Portuguese court of the sixteenth century as reflected in the dramatic novels of Jorge Ferreira de Vasconcellos. [Tesis de la Universidad de Wisconsin, 1953].

10873. Carballo Picazo, A. - Sobre: J. Ferreira de Vasconcellos, Comedia Eufrosina, ed. E. Asensio. - RBD, 5 (1951), 293-295.

10874. REVAH, I. S. - Sobre: J. Ferreira de Vasconcellos, Comedia Eufrosina, ed. E. Asensio. - BHTP, 3 (1952), 267-271. 10875. Ricard, Robert - Sobre: J. Ferreira de Vasconcellos, Comedia Eufrosina, ed. E. Asensio. - LR, 7 (1953), $62-65$.

10876. Hankiss, J. - Sobre: F. de Figueiredo, A épica portuguesa no século $x v i$. - CompL, 4 (1952), 186-187.

10877. Assis Pereira, Carlos DE - Sobre: F. de Figueiredo, $A$ épica portuguesa no século xvi. - RHSP, 2 (1951), 431-436. 10878. Figueiredo, Fidelino DE - "Ainda a épica portuguesa: nótulas de autocritica". - Homenaje a A. M. Hunt. ington (Wellesley, Mass., 1952), 155170 .

10879. Figueiredo, F. de - Camoens y el espiritu épico". - NRFH, 7 (1953), 372-382.

1088o. KrölL, HeINZ - Sobre: H. Houwens Post, Het heroïeke leven van Luis
Vaz de Camoëns. - BdF, 13 (1952), $177-179$.

10881. Camoens, Luis DE - Las [sic] $\mathrm{Lu}$ siadas. Trad. de M. Aranda Sanjuán. [Iberia, Barcelona, 1952]. $23^{8} \mathrm{pp}$. (Col. Obras maestras).

10882. CAMÕEs, Luís DE - Die Lusiaden. Ausgewählt, übertragen und eingeleitet von $\mathrm{O}$. Fr. von Taube. Zweisprachige Ausgabe. - Herder, Freiburg, 1949. $132 \mathrm{pp}$.

10883. Costa Prmpão, A. J. da - "O significado dos Lusiadas". - BUSC, 1950, núms. $55-56$.

10884. RICARD, R. - Sobre: M. Martins, Laudes e cantigas espirituais de Mestre André Dias. $-L R, 7$ (1953), 397-400. 10885. Belchior Pontes, M. DE Lourdes Sobre: Mário Martins, Laudes e cantigas espirituais de Mestre André Dias. $R P F, 5$ (1952), 327-33o.

10886. Cruz e Silva, A. Dinis da - O Hissope. Poema herói-cómico em 8 cantos. Ed. por J. Pereira Tavares. - A. Pinto, Lisboa, $1950.189 \mathrm{pp}$.

10887. M[ARTins], D. - Sobre: A. Vieira, Obras escolhidas, ed. A. Sérgio e H. Cidade. - Bro, 55 (1952), 246-247.

10888. Leme, S. - Sobre: P. A. Vieira, Obras escolhidas, ed. A. Sérgio e H. Cidade - AHSI, 21 (1952), 172-175.

10889. RICARD, R. - Sobre: A. Vieira, Obras escolhidas, ed. A. Sérgio e H. Cidade. $-L R, 8$ (1954), 66-67.

108go. R[Évah], I. S. - Sobre: A. Vieira, Obras escolhidas, ed. A. Sérgio e H. Cidade. - BEPI, 16 (1952), 258-260.

10891. Osókio de Oliveira, José - Visão incompleta de meio século de literatura portuguesa. - Portugália, Lisboa, $195^{\circ}$. $3^{8} \mathrm{pp}$.

10892. Couceiro Freijomil, Antonio Enciclopedia gallega. I: Diccionario biobibliográfico de escritores. T. 1: A-E. Bibliófilos Gallegos, Santiago de Compostela, $1951.402 \mathrm{Pp}$.

10893. Pereira, Lúcia Miguel - "Cinquenta anos de literatura [brasileña]".$P W, 1$ (1952), núm. 1, 28-48.

10894. Mendonça, Renato de (ed. y trad.) - Antologia de la poesia brasileña. Cultura Hispánica, Madrid, 1952. 305 pp.

10895. Castello, J. Aderaldo - "Apontamentos para a história do simbolismo no Brasil". - Rev. da Univ. de São Paulo, $195^{\circ}$.

10896. Rezende, Carlos P. de - "Castro Alves". - Investigaçōes (São Paulo), 3 (1951), núm. 35, 35-61. 
10897. Correia Pacheco, A. - Graça Aranha: La obra y el hombre. - Unión Panamericana, Washington, 1951. $14^{\circ}$ pp.

10898. Alatorre, Antonio - "Graça Aranha, novelista y pensador". - CuA, 12 (1953), núm. 6, 259-274.

10899. Veríssimo, ERICo - O tempo e o vento. II: $O$ retrato. - Globo, Pôrto Alegre, 1951. 594 pp.

1090o. Verfssimo, Érico - Time and the wind. Trad. L. L. Barrett.-Macmillan, New York, 1951. 624 pp.

10901. LimA, JORGe DE - Poemas. Ed. F. Villa Alvarez. 2a ed. - Konfino, Rio de Janeiro, 1952. 176 pp.

10g02. Entrambasaguas, J. DE - "Literatura brasileña. La poesía de Jorge de Lima". - RLit, I (1952), 469-473.

V. también núms. 10710, 10712, 10720, $10727-30$.

\section{LITERATURA ESPAÑOLA E HISPANOAMERICANA}

\section{Historia literaria}

E.s $p$ a $\tilde{n} a$

10903. LARRIEU, Robert, et Romain ThoMAs-Histoire illustrée de la littérature espagnole. Précis méthodique. Préf. de Paul Crouzet. - Didier, Paris, 1952. xviii + 492 pp., ilustr.

10904. TORRI, JULIo - La literatura española. - Fondo de Cultura Económica, México, 1952. $3^{87}$ pp. (Col. Breviarios). 10905. V[Albuena] P[RAT], A. - Sobre: J. Torri, La literatura española. - Clav, 4 (1953), núm. 23, p. 78.

10go6. Risco, Alberto - Historia de la literatura española y universal. $14^{\mathrm{a}}$ ed. - Razón y Fe, Madrid, 1951.-V. RFH, núm. 6967 .

10907. Gilt Gaya, S. - Iniciación en la historia literaria española. $2^{\mathrm{a}}$ ed.-Spes, Barcelona, 1952. 120 pp.

10go8. Menéndez Pidal, Ramón - Miscelánea histórico-literaria. - Espasa-Calpe, Buenos Aires, 1952. 145 pp. (Col. Austral, 1110).

109o9. R[ENoUARD], Y. - Sobre: E. S. Procter, Alfonso X of Castile, patron of literature and learning. - $\mathrm{BHi}, 54$ $\left(195^{2}\right), 43^{8-439}$.

10910. Russel, P. E. - Sobre: E. S. Procter, Alfonso $\mathrm{X}$ of Castile, patron of literature and learning. - $M L R, 4^{8}$ (1953), 88-9o.

10911. Caso González, José - Sobre: A.
Zamora Vicente, Presencia de los clásicos. - AO, 2 (1952), 327-329.

10912. Cisneros, Luis Jaime - Sobre: A. Zamora Vicente, Presencia de los cla. sicos. - MdS, 8 (1952), núm. 24, 92-93. 10913. LAzaro Carreter, F. - Sobre: A. Zamora Vicente, Presencia de los clásicos. - Ins, 7 (1952), núm. 84.

10914. WADE, G. E. - Sobre: A. Zamora Vicente, De Garcilaso a Valle-Inclán. $B A b r, 26$ (1952), 387-388.

10915. Green, Otis H. - Sobre: Ricardo del Arco y Garay, La erudición española en el siglo xvii y el cronista de Aragón Andrés de Uztarroz. - HR, 21 (1953), 87-88.

10916. Salinas, Pedro - "El romanticismo y el siglo xx". - Homenaje a $A$. $M$. Huntington (Wellesley, Mass., 1952), 499-527.

10917. Llorens, Vicente - "Una publicación romántica olvidada". - NRFH, 7 (1953) , 279-29o. [Los No me olvides, editados por J. J. de Mora y P. Mendibil (1824-1829)].

10918. Claveria, Carlos - Cinco estudios de literatura española moderna. - Salamanca, 1945. $118 \mathrm{pp}$. (Tesis y estudios salmantinos, II).

10919. Alvar, Manuel - Sobre: C. Clavería, Cinco estudios de literatura espanola moderna.-RF, 65 (1953), 191-193. 10920. PAsquale, Roberto DI - Sobre: G. Torrente Ballester, Literatura española contemporánea. - Sur, 1952, núms. 209. 210, pp. 139 ss.

\section{Hispanoamérica}

10921. AlbA, V. - "Les indiens et la naissance de la littérature latino-américaine". - Preuves, marzo de $195^{2}$.

10922. Giusti, Roberto F. - Sobre: M. P. González, Estudios sobre literaturas hispanoamericanas. - CurCon, 43 (1953), $125^{-127}$.

10923. Mead, Robert G., JR. - Sobre: M. P. González, Estudios sobre literaturas hispanoamericanas. - HispB, 35 (1952), 252.

10924. Téllez, Hernando - Literatura. Argra, Bogotá, 1951. 263 pp.

10925. FerRAndiz Alborz, F. - "Tres precursores del nuevo realismo literario hispanoamericano". - CuA, 11 (1952), núm. 6, 266-284. [D. F. Sarmiento, E. Acevedo Díaz y Luis A. Martinez].

10926. LAzo, RAImundo - "Caracterización y balance del modernismo en la literatura hispanoamericana". - CuA, 11 (1952), núm. 4, 242-251. 
10927. Anderson Imbert, E. - "Comienzos del modernismo en la novela”. NRFH, 7 (1953), 515-525.

10g28. Loynaz, Dulce MA. DE - "Influencia de los poetas cubanos en el moder nismo". - CuH, 18 (1954), 5 1-66.

1og29. Martínez, José Luis - "Dos historiadores de la literatura mexicana" [Ignacio M. Altamirano y Francisco Pimentel]. - Memoria del primer congreso de historiadores... Monterrey, 1949 (México, 1951), pp. 180-195.

10930. A [urrun], C. V. - Sobre: José Sánchez, Academias y sociedades literarias de México. - BHi, 54 (1952), 103-104. 10931. LEONARD, IRving A. - Sobre: José Sánchez, Academias y sociedades literarias de México. - HispB, 35 (1952), 254-255.

10932. Robe, Stanley L. - Sobre: José Sánchez, Academias y sociedades literarias de México. - HR, 21 (1953), 174. 176 .

10933. Alcalá, Manuel - Sobre: José Luis Martínez, Literatura mexicana, siglo $x x .-H R, 21$ (1953), 77-79.

10934. Cambours Ocampo, Arturo - Indagaciones sobre literatura argentina. Albatros, Buenos Aires, 1952. $92 \mathrm{pp}$.

10935. Ferres Cordero, Julio - Sobre: E. Espinoza, El espiritu criollo. Sarmiento. Hernández. Lugones. - RBN, 3 (1952), núm. 1, 203-204.

\section{Temas literarios}

10936. Lida de Malkiel, Marfa Rosa "La métrica de la Biblia: un motivo de Josefo y San Jerónimo en la literatura española". - Homenaje a $A$. M. Hun tington (Wellesley, Mass., 1952), 335-359. 10937. Bataillon, M. - "La tortolica de Fontefrida y del Cántico espiritual". NRFH, 7 (1953), 291-3o6.

10938. SPITZER, iEO - "Auf keinen grünen Zweig kommen". - MLN, 69 (1954), 270-273. [Sobre el giro "no posar en ramo verde", del romance de Fontefrida].

10939. Gillet, J. E. - "El mediodía y el demonio meridiano en España". NRFH, 7 (1953), 307-315.

10940. Ubieto Arteta, A. - "Un Pedro Urdemalas del siglo xir". - AFAr, 5 (1953), $17^{0-174}$.

10941. Castro Pires de Lima, Ffrnando - A sereia. Pról. de Gregorio Marañón. - Pôrto Editora, Pôrto, [1952]. 205 pp. [El tema de la sirena en Grecia, en Roma y en los paises modernos, sobre todo España y Portugal].
10942. BénICHou, P. - "El casamiento del Cid". - NRFH, 7 (1953), $3^{16-33^{6}}$.

10943. Rossi, G. C. - Sobre: José López de Toro, Los poetas de Lepanto. QIA, 2 (1953), p. 293.

10944. Weinstern, Leo - A critical study of the Don Juan legend. - [Tesis de Ia Univ. de Stanford, 1951].

10945. Chekhov, ANton - Don Juan (in the Russian manner). English version by Basil Ashmore. Pref. by Sir Desmond MacCarthy. - Nevill, London, 1952. $127 \mathrm{pp}$.

10946. Doolittle, James - "The humanity of Molière's Dom Juan". - PMLA, 68 (1953), 509-534.

10947. LabiaU, L. - Sobre: Esther van Loo, Le vrai don Juan, don Miguel de Mañara. - LR, 6 (1952), 350-352.

10948. Sauvage, Micheline - Le cas Don Juan. - Éd. du Seuil, Paris, 1953. 208 pp. (Coll. Pierres vives).

10949. Worthington, Mabel - Don Juan: theme and development. - [Tesis de la Univ. de Columbia, 1952].

10950. Schuster, EDWARD J. - "Yo, el rey". A study of the development of monarchical absolutism in the Spanish Golden Age and its infuence on the literature of the period. - [Tesis de la Univ, de Minnesota, 1951].

1095 1. R[ossi], G. C. - Sobre: G. Guastavino Guallent, Los bombardeos de Argel en ${ }_{17} 8_{3}$ y ${ }_{17} 84$ y su repercusión literaria. - QIA, 2 (1953), 293-294.

10952. Ferrándiz Alborz, F. - "El indio, nueva realidad literaria hispanoamericana”. - CCL, 1953, núm. 3, 25-91.

10953. Gonzálfz, Beatrice. E. - "The emergence of the Indian in Mexican imaginative literature". - Bucknell Univ. Studies, 2 (1951).

\section{POESIA}

10954. Menéndez Pidal, R. - De primitiva lirica española y antigua épica. Espasa-Calpe, Buenos Aires, 1951. 161 pp. (Col. Austral, 1051).

10955. Menéndez Pidal, Ramón - "Para la definición de la poesía tradicional". - CuH, 17 (1953), ${ }_{159-164 .}$

10956. Morby, E. S. - Sobre: Dámaso Alonso, Poesía española. Ensayo de métodos y limites estilisticos. - Clav, 3 (1952), núm. 17, 39-42.

10957. Richthofen, Erich Fr. vor - Sobre: D. Alonso, Poesía española. Ensayo de métodos y limites estilisticos. - AIL, 5 (1952), 404-410.

10958. Páez Patiño, R. - Sobre: D. Alon- 
so, Poesia española. Ensayo de métodos $y$ limites estilisticos. - BICC, 8 (1952), 224-228.

10959. H[ATZFELD], H. - Sobre: D. Alonso, Poesia española. Ensayo de métodos y limites estilisticos. - CompL, 4 (1952), $87-89$.

10960. Arce, J. - Sobre: D. Alonso, Poesia española. Ensayo de métodos y li. mites estilisticos. $-R L M, 195^{2}$, núm. 1. 1og61. Spitzer, Leo - Sobre: D. Alonso, Poesia española. Ensayo de métodos y limites estilisticos. - RF, 64 (1952), 213 . 240.

10962. RüEgG, A. - Sobre: D. Alonso, Poesia española. Ensayo de métodos y limites estilisticos. - ZRPh, 68 (1952), 143-149.

10963. Morby, EDwin S. - "Un caveat para la crítica: observaciones en torno a una teoría de la nueva escuela". Clav, 3 (1952), núm. 17, 39-42. [Acerca de Poesia española, de Dámaso Alonso].

\section{Métrica}

10964. Navarro, Tomás - "El octosílabo y sus modalidades". - Homenaje a $A$. $M$. Huntington (Wellesley, Mass., 1952), $435-455$.

10965 . Cinellada de Zamora, Ma. Josefa - "Notas de métrica. Ritmo en unos versos de romance". - NRFH, 7 (1953), 88-94.

10966. Correa, Gustavo - Sobre: E. Segura Covarsí, La canción petrarquista en la lírica española del Siglo de Oro. - CompL, 4 (1952), 283-286.

$\log _{67}$. Spina, S. - Sobre: E. Díez Echarri, Teorias métricas del Siglo de Oro. - RHSP, 4 (1952), 233-235.

10968. Clarke, Dorothy C. - "Some observations on Castilian versification of the neoclassical period". - $H R, 20$ (1952), 223-239.

V. También núm. 11111.

\section{Cancioneros y antologias}

1og69. Menéndez Pelayo, M. - Antologia de poetas liricos castellanos. $10 \mathrm{ts}$. Espasa-Calpe, Bucnos Aires, 1952. - V. núm. 455 .

10970. Schalk, F. - Sobre: E. Allison Peers (ed.), A critical anthology of Spanish verse. - RF, 64 (1952), 211-213. 10971. Perry, Janet H. (ed.) - The Heath anthology of Spanish poetry. D. C. Heath and Co., s. f. 468 pp. 10972. SchokeL, L. A. (ed.) - Poesia es- pañola. $2^{\text {a }}$ ed. - A. Aguado, Madrid, 1952. $360 \mathrm{pp}$. (Col. Más allá).

10973. Lumsden, Audrey - Sobre: Ch.V. Aubrun (ed.), Le Chansonnier espagnol d'Herberay des Essarts.-BHS, 29 (1952), 58-60.

10974. McPhezters, D. W. - Sobre: Ch. V. Aubrun (ed.), Le Chansonnier espagnol d'Herberay des Essarts.-RRQ, 44 (1953), 136-139.

10975. Green, Otis H. - Sobre: Ch.-V. Aubrun (ed.), Le Chansonnier espagnol d'Herberay des Essarts. - HR, 21 (1953), 162-164.

10976. Groult, P. - Sobre: Ch.-V. Aubrun (ed.), Le Chansonnier espagnol d'Herberay des Essarts. - LR, 7 (1953), 401-404.

10977. Gallego Morell, A. - Sobre: A. Rodríguez-Moñino, El cancionero manuscrito de Pedro del Pozo. - Arb, 21 (1952), 149-151.

10978. Cancionero de obras de burlas provocantes a risa. Ed. facs. de la impresa en Valencia por Juan Viñao en 1519. - Valencia, 1951.

10979. Velázquez de Ávil.A - Cancionero gótico. Pról. de A. Rodríguez-Moñino. - Castalia, Valencia, 1951. $118 \mathrm{pp}$. 10g8o. Fucilla, Joseph G. - Sobre: Cancionero antequerano, ed. D. Alonso y R. Ferreres. - HR, $20\left(195^{2}\right), 1^{175}$ 181 .

IOg81. Gallego Morell, A. - Sobre: Cancionero antequerano, ed. D. Alonso y R. Ferreres. - $A r b, 21$ (1952), 149151.

10982. López Estrada, F. - "Nueva luz sobre la poesía antequerana".-AHisp, 15 (1950 I), núm. 5o, 257-263.

\section{Lírica}

\section{Es $p$ a $\tilde{n} a$}

10983. Jacob, Alfred - "The Razón de amor as christian symbolism". - $H R$, $20(1952), 282-301$.

Iog84. Piccus, Jules - Expressions for color in Old Spanish poetry. - [Tesis de la Univ. de Princeton, 1951].

10985. Zertuche, Francisco M. - "El Marqués de Santillana". - $A y L, 9$ (1952), núm. 8.

10g86. Spitzer, Leo - "A passage of Santillana's Serranilla $V^{\prime \prime} . \quad-H R, 21$ (1953), $135^{-1} 3^{8}$.

10987 . Santillana, Marqués de - Poesias. - Fama, Barcelona, [1953]. 131 pp. 10g88. Cano, J. L. - Sobre: A. Gallego Morell, Dos ensayos sobre poesía espa. 
ñola del siglo xvi. - Ins, 7 (1952), núm. 75 .

10989. Segura Covarsí, E. - "Don Jerónimo de Lomas Cantoral: un petrarquista olvidado". - RLit, 2 (1952), 3975 .

1099o. Fucilla, Joseph G. - "Nuove imitazioni di Fernando de Herrera". QIA, 2 (1953), 241-249. [Sobre la influencia de Petrarca y Tansillo].

10991. BlecuA, J. M. - "La sensibilidad de Fernando de Herrera (Tres notas para su estudio)". - Ins, 8 (1953), núm. 86.

10992. López Estrada, F. - Estudio y edición del "Tomás Moro" de Fernando de Herrera. - Sevilla, 1950. 49 pp. 10993. Aldana, Francisco de - Obras completas. Ed. de M. Moragón Maestre. - [C.S.I.C.], Madrid, 1953. 2 ts.: xiv + 235 y 271 pp.

10994. Rivers, Elias LyNCH 3RD - The life and works of Francisco de Aldana. - [Tesis de la Universidad de Yale, 1952].

10995. Rivers, Elias L. - "New biographical data on Francisco de Aldana".$R R Q, 44$ (1953), 166-184.

10996. Romera-Navarro, M. - Sobre: Pedro Laynez, Obras, ed. J. de Entrambasaguas. - HispB, $3^{6}$ (1953), 125126.

10997. Sarmiento, E. - Sobre: Pedro Laynez, Obras, ed. J. de Entrambasaguas. - $M L R, 4^{8}$ (1953), $4^{82-483}$.

10998. Jeffers, R. - Poetry, Gongorism and $A$ thousand years. - Los Angeles, $195^{\circ}$.

10999. Rossi, G. C.-Sobre: Gaspar Aguilar, Rimas humanas y divinas, ed. F. de A. Carreres de Calatayud. - $Q I A$, 2 (1953), 286-287.

11000 . Fucilla, J. G. - Sobre: Gaspar Aguilar, Rimas humanas y divinas, ed. A. Carreres de Calatayud. - HR, 22 (1954), 78-79.

1lool. Carreres de Calatayud, A. - "El color en la poesía de Gaspar Aguilar". - EMP, 3, 229-236.

11002. Mettmann, Walter - Sobre: D. Alonso, Vida y obra de Medrano.-RF, 65 (1953), 199-201.

11003. Fucilla, JosePH G.-"Petrarchism in the poetry of the Argensolas". $H R, 20$ (1952), 200-211.

11004. Fugilla, Joseph G. - Sobre: L. y B. Leonardo de Argensola, Rimas, ed. J. M. Blecua. - HR, 20 (1952), 72-75. 11005 . Martínfz Cachero, J. M. - Sobre: L. y B. Leonardo de Argensola,
Rimas, ed. J. M. Blecua. - AO, 2 (1952), 323-324.

11006. Green, Otrs H. - "Bartolomé Leonardo de Argensola y el Reino de Aragón". - AFAr, 4 (1952), 7-112.

11007 . MEjía SÁNCHEz, E., y LuIs A. Ratro - "Poesías inéditas del Príncipe de Esquilache". - NRFH, 7 (1953), $35^{2-363 .}$.

11008. LABiaU, L.-Sobre: H. Juretschke, Vida, obra y pensamiento de Alberto Lista. - LR, 8 (1954), 69-7o.

lloog. Staubach, Charles N. - Sobre: H. Juretschke, Vida, obra y pensamiento de Alberto Lista. - HR, 21 (1953), 243-246.

11010. Rumeau, A. - Sobre: H. Juretschke, Vida, obra y pensamiento de Alberto Lista. - BHi, 54 (1952), 211215.

11011. Alberti, Rafael - Retornos de lo vivo lejano. - Losada, Buenos Aires, 1952. 166 págs.

11012. Alberti, Rafael - Poèmes. Texte espagnol et trad. par Guy Lévis Mano. - Gallimard, Paris, 1953. 120 págs. 11013. Olivero, Federico - "Sul lirismo di Sobre los ángeles di Rafael Alberti". - Vita e Pensiero, 35 (1952), marzo-mayo.

11014. Olivero, F. - "Su Sobre los ángeles, di Rafael Alberti". - QIA, 2 (1953), 256-258.

11015. Bajarlía, Juan Jacobo - "Origenes del vanguardismo en la poesía castellana". - $A, 105$ (1952), núms. 319320.

11016. Vocos Lescano, Jorge - "Tres libros españoles". - $B A L, 195^{2}$, núm. 3, $5^{1-57}$. [Sobre obras recientes de Luis Cernuda, Blas de Otero y Julián Ayesta].

V. también núms. $10717-19$.

García Lorca

11017. Río, ÁNGel DEL - Vida y obras de Federico Garcia Lorca. - Heraldo de Aragón, Zaragoza, 1952. 168 pp. (Estudios literarios, 3) .

11018. Beardsley, W. A. - Sobre: A. del Rio, Vida y obras de Federico Garcia Lorca. - HispB, 36 (1953), 249-250.

11019. Campbell, Roy - Federico Garcia Lorca: An appreciation, with selected translations of his poetry. - Yale Univ. Press, New Haven, 1952. 79 pp.

11020. Cano, J. L. - Sobre: Roy Campbell, Federico García Lorca. - Clav, 4 (1953), núm. 21, 73-74.

11021. Carbonell, ReYes - Sobre: Roy Campbell, Federico Garcia Lorca. - Es. 
tudios (Duquesne Univ.), 2 (1953), núms. $6-7,7^{1-73}$.

11022. Barea, Arturo - "Federico García Lorca. El poeta y el pueblo". Núm, 4, (1952), 195-146. - V. núm. $814^{2}$.

11023. García Lorca, Federico - Romancero gitano. $8^{\mathrm{a}}$ ed. - Losada, Buenos Aires, 1953. (Obras completas).

11024. García LorCa, Federico - Lament for the death of a bullfighter and other poems. Trad. A. L. Lloyd. - Heinemann, London, 1952.65 pp. - V. $R F H$, núm. 1160 .

11025. Salinas, P. - "Lorca and the poetry of death". - Hopkins Review, 5 (1951).

11026. Xirau, Ramón - "La relación metal-muerte en los poemas de García Lorca". - NRFH, 7 (1953), 364-371.

11027. García Lorca, F. - Teatro. Pref. e trad. di V. Bodini. - Einaudi, Torino, $195^{2}$.

11028. Giacheri, R. - Sobre: F. García Lorca, Teatro, trad. V. Bodini. - $Q I A$, 2 (1953), p. 292.

11029. Garcfa Lorca, Federico - La zapatera prodigiosa, Edited by Edith F. Helman. - W. W. Norton and Co., New York, 1952. 192 pp.

110zo. García Lorca, Federico - La casa de Bernarda Alba. Prosas póstumas. $3^{\text {a }}$ ed. - Losada, Buenos Aires, 1953 (Obras completas 8). - V. núm. $115^{8}$.

1031. DugherA, Eduardo A. - Un aspecto de "La casa de Bernarda Alba".Universidad Nacional del Litoral, Santa Fe, 1952. 22 pp. (Extensión universitaria, publ. 66).

11032. BoRdiER, ROGER - “À propos de Lorca et de théâtre”. - Io (Paris), 2 (1952), núm. 7 .

SALINAS

11033. Helman, Edith F. - "Pedro Salinas: a tentative bibliography". HispB, 35 (1952), 156-159.

11034. PANe, Remigio U. - "A bibliography of Salina's works in English traduction". - HispB, 35 (1952), 159-160. 11035. Salinas, Pedro-Razón de amor.Losada, Buenos Aires, 1952. 96 pp.

11036. Urtubey, J. H. - Sobre: Pedro Salinas, Razón de amor. - Sur, 195², núms. $215 / 6,124-125$.

11037. Salinas, Pedro - Teatro. La cabeza de medusa. La estratósfera. La isla del tesoro. - Insula, Madrid, $195^{2}$. 141 pp. (Col. Insula, 7).

11038. Rodrfguez Monegal, E. - Sobre:
Pedro Salinas, Teatro.-Núm, 4 (1952), 292-293.

11039. Salinas, Pedro - Ella y sus fuentes. - Núm, 4 (1952), 11-39. [Comedia en un acto].

11040. Salinas, Pedro - Los santos. CuA, 13 (1954), núm. 3, 264-291. [Drama en un acto].

11041. Salinas, Pedro - "Les pouvoirs de l'écrivain ou les illusions perdues". Hommage à Balzac (Paris, 1950).

11042. "Vida y obra [de Pedro Salinas]".Num, 4 (1952), 93-95.

11043. [SAlinas, Pedro] - Homenaje a Pedro Salinas. - HispB, 35 (1952), 13116o. [Colaboran: N. B. Adams, V. Aleixandre, M. Bataillon, J. M. Blecua, G. Correa, A. del Rio, G. Diego, J. E. Englekirk, J. Ferrater Mora, E. Florit, S. Gilman, J. Guillén, R. Gullón, E. F. Helman, J. Marías, L. Muñoz Marín, M. C. Rand, M. Romero, J. Sarrailh, C. Castro de Zubiri].

11044. Alonso, D. - "Carta última a don Pedro Salinas". - $\mathrm{CuH}, 11$ (1952), 5054 .

11045. Alonso, D. - "Con Pedro Salinas". - Clav, 1951, núm. 11, 16-19.

11046. Alonso, D. - "España en las cartas de Pedro Salinas". - Ins, 7 (1952), núm. 74 .

11047. Alvarez Morales, M. - "Pedro Salinas, maestro y creador". - Lyc, 8 (1952), núm. 30, 67-9o.

11048. Aparicio, Francisco - "Pedro Salinas y La bomba increible". - RyF, 145 (1952), 184-19o.

11049. Arana, José Ramón - "Escritores españoles en el destierro: Pedro Salinas". - Ho, 1952 , núm. $4,44-47$.

11050. B[ataillon], M. - "Pedro Salinas". - BHi, 54 (1952), $112-116$.

$110_{5} 1$. Blanco, TOMÁs - "La estancia en la isla" [Pedro Salinas en Puerto Rico]. - Asom, 1952, núm. 2, 54-63.

$110_{5}^{2}$. Bravo-Villasante, Ciarmen - "La poesía de Pedro Salinas". - Clav, 4 (1953), núm. 21, 44-52.

11053 . BRUNICARDI, R. - "Inocencia y lengua poéticas de Pedro Salinas. (Ensayo para místicos)". $-C U, 1951$, núm. $28,25-30$.

11054. Capote, Higinio - "Memoria de Pedro Salinas". - EstA, 4 (1952), 55-62. 11055 . Carrera ANDrade, Jorge - "Elegía a Pedro Salinas".-Asom, 1952, núm. 3, $14^{-16 .}$

11056. DoReste, V. - "Claridad y rigor en la poesía de Salinas". - Ins, 7 (1952), núm. 74 . 
11057. Espina, Antonio - "Salinas, visto de prisa". - Asom, 1952, núm. 2, 81-83. 11058 . FERnÁndez MÉndez, E. - "Pedro Salinas: Quijote moderno". - Asom, 1952, núm. 2, 84-86.

11059. Gallego Dfaz, J. - "Pedro Salinas, con Sevilla al fondo". - Ins, 7 (1952), núm. 75 .

11060. Garcia BLANCo, M. - "Últimos recuerdos de Pedro Salinas". - Ins, 7 (1952), núm. 82.

11061. Gillet, Joseph E. - "Pedro Salinas (1892-1951)". - HR, 20 (1952), p. 267 .

11062. Guerrero Ruiz, J. - "Pedro Salinas: Apuntes para una bibliografía". Ins, 7 (1952), núm. 75 .

11063. GuILLEN, JORGE - "El atento" [Pedro Salinas]. - Asom, 1952, núm. 2, 27-31.

11064. GuIllén, JoRge - "Mientras hubo..." - Ins, 7 (1952), núm. 74. [Sobre Pedro Salinas].

11065. Guillén, Jorge - "Profesión y ofcio". - Núm, 4 (1952), 5-10. [Sobre Pedro Salinas].

11066. Gullón, Ricardo - "La poesía de Pedro Salinas". - Asom, 1952, núm. 2, $32-45$.

11067. Liorens, Vicente - "El desterrado y su lengua. Sobre un poema de Salinas". - Asom, 1952, núm. 2, 46-53.

11068. Rodríguez Monegal, E. - “Obra en prosa de Salinas". - Núm, 4 (1952), 66-92.

11069. SÁNCHEz, LuIs AMAdOR - “Tránsito de Pedro Salinas". - ND, 32 (1952), 2, 27-29.

11070 . Santullano, Luis - "El porqué de su último deseo" [de Pedro Salinas]. Asom, 1952, núm. 2, 77-80.

11071 . Vilariño, IdEA - "La poesía de Salinas". - Núm, 4 (1952), 54-65.

11072. WARDROPPER, BRUCE W. - "Pedro Salinas". - $M L N, 67$ (1952), p. 72.

\section{Hispanoamérica}

11073. Varela, Joste Luis - Ensayos de poesia indigena en Cuba.-Cultura Hispánica, Madrid, 1951. 124 pp.

11074 . Baeza Flores, A. - Sobre: J. L. Varela, Ensayos de poesia indigena en Cuba. - RBN, 4 (1953), núm. 3, 181183.

11075. Vila Selma, J. - Sobre: J. L. Varela, Ensayos de poesia indigena en $\mathrm{Cu}$ ba. - Arb, 19 (1951), 584-585.

11076. Monner SAns, Jost MA. - Julián del Casal y el modernismo hispanoame- ricano. - El Colegio de México, México, 1952. 273 pp. - V. núm. 7477.

11077 . Giusti, Roberto F. - Sobre: J. M. Monner Sans, Julián del Casal y el modernismo hispanoamericano. - CurCon, 43 (1953) , 297-240.

11078. Guardia, Miguel - "De la soledad al optimismo en la poesía mexicana". - FyL, 21 (1951), 43-63.

11079. Rivas Sáinz, Arturo - La poesia de Enrique González Martinez.-Xallixtlico, Guadalajara, México, [1951]. 42 pp.

11080. Tamayo Vargas, A. - "Enrique González Martínez, poeta buho".-MdS, 1952, núm. 21, 69-z6.

11081. Topere, José M. - "González Martínez y la crítica". - RevIb, 16 (1952), $255-268$.

11082. TopeTE, José M.-The poetic world of E. González Martinez. - [Tesis de la Univ, de Southern California, 1950].

11083. Valle, R. H. - "El mundo poético de González Martínez". - $A y L, 9$ (1952), núm. 8.

11084. Abreu Gómez, E. (ed.) - Rubén Dario, critico literario. Temas americanos. - Unión Panamericana, Washington, $195^{1}$. $141 \mathrm{pp}$.

11085 . Moser, Gerald - Sobre: E. Abreu Gómez (ed.), Rubén Dario, critico literario. - HispB, 35 (1952), 375-376.

11086. Ratto, L. A. - Sobre: E. Mejía Sánchez, Los primeros cuentos de Rubén Dario. - MdS, 8 (1952), núm. 24, 90-92.

11087. Ycaza Tigerino, J. - "Rubén Darío o el carnalismo americano”. - $Q I A$, 2 (1952), 196-199.

11088. Beardsley, Wilfred A. - Sobre: Sonja Karsen, Guillermo Valencia, Colombian poet. - HispB, 35 (1952), 38o$3^{81 .}$

11089. Peers, E. Allison - Sobre: Sonja Karsen, Guillermo Valencia, Colombian Poet. - BHS, 29 (1952), 169.

110 o. SÁnchez, Luis A. - Sobre: Sonja Karsen, Guillermo Valencia, Colombian poet. - ND, 32 (1952), núm. 3, 68-69. 1log1. Torres-Rioseco, A. - Sobre: Sonja Karsen, Guillermo Valencia, Colombian poet. - HR, 21 (1953), 251.

11092. ENGLEKIRK, JoHN E. - Sobre: S. Karsen, Guillermo Valencia, Colombian poet (1873-1943) - HAHR, 32 (1952), $605-606$.

11093. Andía, Ernesto Daniel - Diagnosis de la poesia y su arquetipo. - El Ateneo, Buenos Aires, 1951. 335 pp. 44 
láms. [Su "arquetipo" es el peruano AIberto Hidalgo].

11094. Neruda, Pablo - Veinte poemas de amor y una canción desesperada. $4^{\mathrm{a}}$ ed. - Losada, Buenos Aires, 1952. 108 pp.

$1 \log _{5}$. Echeverrí, Esteban - Obras completas. Ed. por J. M. Gutiérrez, J. P. Barreiro y E. Joubín Colombres. $-\mathrm{Za}$ mora, Buenos Aires, 1951. 1055 pp.

11096. Lugones, Leopoldo - Obras poéticas completas. Pról. de Pedro Miguel Obligado. 2a ed. - Aguilar, Madrid 1952. 1518 pp. - V. núm. 2254.

11097. Russell, Dora ISElla - Juana de Ibarbourou. - Montevideo, 1951. 35 pp.

$1 \log 8$. JeAn Morente, Antonio - "Juana de Ibarbourou y sus nuevos poemas". $-C C E$, 3 (1950), núm. 9, 193-203.

11099. Nalé Roxlo, Conrado - De otro cielo. - Roggero, Buenos Aires, 1952. $116 \mathrm{pp}$.

11100. Alonso Gamo, J. M. - Tres poe. tas argentinos. - Cultura Hispánica, Madrid, 1951.

Sor JUANA

11101. Cruz, Sor Juana Int́s de la-Obras completas. Ed., pról. y notas de Alfonso Méndez Plancarte. T. 2: Villancicos $y$ letras sacras. - Fondo de Cultura Económica, México, 1952. Ixxviii + $55^{\circ} \mathrm{pp}$. (Biblioteca americana, 21) - V. núm. 9755 .

1102. Lazo, RaImundo-"'Sor Juana Inés de la Cruz". - $A A N H, 33(1951), 165$. 186.

11103. GARcÉs, ENRIQUe - Juana Inés de la Cruz. - Quito, $195^{1 .}$
11104. Royer, FANCHón - The Tenth Muse: Sor Juana Inés de la Cruz.-St. A Guild Press, Paterson (New Jersey), 1952. xii + 192 pp.

11105 . Healy, M. Aquinas - Sobre: F. Royer, The Tenth Muse: Sor Juana Inés de la Cruz. - Amer, 1o (1953-54), 243-244.

11 106. Linero, MAgdalena - "Sor Juana Inés de la Cruz". - RFFH, 3 (1951), 285-315.

11107. Enrfouez Calleja, Isidoro - Las tres celdas de Sor Juana.-México, 1953. (Col. Aquelarre).

11108 . Puga, Mario - Sobre: I. Enríquez Calleja, Las tres celdas de Sor Juana. Ho, 1953, núms. 11-12, 140-141.

11109 . Garcés, Jesús Juan - Vida y poesia de Sor Juana Inés de la Cruz. Cultura Hispánica, Madrid, 1953. 174 pp. (Col. Hombres e ideas).

11110. Cerezales, Manuel G. - Sobre: J. J. Garcés, Vida y poesia de Sor Juana Inés de la Cruz. - Arb, 26 (1953), 163-164.

11111. Navarro, Tomás - "Los versos de Sor Juana”. - RomPh, 7 (1953-54), 4450.

11112. López Narváez, Carlos - "De lo profano a lo divino en la lírica amorosa de Sor Juana Inés de la Cruz".$U d A, 1951,991-1020$.

11113. LEAL, LUIS - "El 'tocotín mestizo' de Sor Juana". - $A b s, 18$ (1954), 51-64.

11114. Hernández de Mendoza, Cecilia "Sor Juana Inés de la Cruz y su símbolo".-Bol, 1952, núm. 15 .

11115 . Salceda, Alberto G. - "Cronología del teatro de Sor Juana". - $A b s$, 17 (1953), 333-358. 